\title{
CAMBIO ELECTORAL EN ESPAÑA EN 1982: REALINEAMIENTO POLARIZADO *
}

\author{
POR \\ GIACOMO SANI y GOLDIE SHABAD \\ Departamento de Ciencias Políticas \\ Ohio State University
}

Los regímenes democráticos son frágiles, y los sistemas democráticos nuevos resultan particularmente vulnerables. Su supervivencia se encuentra amenazada por diversas fuentes internas y externas. Entre läs últimas, es importante el grado de polarización del sistema político. La polarización puede provocar un conflicto abierto o conducir a una inestabilidad crónica y a una parálisis con serias consecuencias para el funcionamiento y la efectividad del régimen. Más grave aún es la posibilidad de que la polarización pueda crear una atmósfera que aliente intentos de derrocar o cambiar significativamente el sistema democrático ${ }^{1}$.

La ausencia del consenso en el nivel de la elite sobre las reglas de juego o sobre las dimensiones de los principales problemas, especialmente cuando ello va acompañado de «elites críticas», tiene probablemente una significación inmediata mayor que la polarización a nivel de masas. Pero dado que las tensiones entre los ciudadanos condicionan el comportamiento de las elites políticas, no se puede ignorar las escisiones profundas y los sentimientos recíprocos y fuertemente arraigados de hostilidad que separan amplios segmentos de la población.

Dada la conflictiva historia de España y el hecho de que la democracia no se encuentre todavía plenamente institucionalizada, las variaciones en el grado de consenso son particularmente importantes para el joven régimen español. La forma de Gobierno ha sobrevivido satisfactoriamente la delicada fase de la transición y el nuevo régimen se ha mantenido a lo largo de los cuatro años que han pasado desde que se aprobara la Constitución. Pero las amenazas a su super-

* Este estudio es una versión modificada de dos trabajos presentados por los autores en el Seminario sobre política española, celebrado en Bad Homburg, Alemania, del 30 de junio al 2 de julio de 1983.

${ }_{1}$ El papel que la polarización ha desempeñado en las quiebras de los sistemas democráticos se encuentra abundantemente ilustrado en los estudios monográficos incluidos en el volumen The Breakdown of Democratic Regimes, editado por Juan Linz y Alfred Stepan, Baltimore, y The Johns Hopkins University Press, Londres, 1978. Véase también Giovanni Sartori, Parties and Party Systems, vol. I, Cambridge, Cambridge University Press, 1976, espec. págs. 145-172. 
vivencia no han desaparecido totalmente y la futura estabilidad del régimen no puede considerarse garantizada. Un florecimiento de las tensiones, si no son hábil y responsablemente conducidas por las elites políticas, podría fácilmente poner en peligro los logros del período 1976-1982.

Un estudio ha demostrado que, a finales de los setenta, el sistema español se encontraba moderadamente polarizado por cuanto se refiere a las tensiones ${ }^{2}$ religiosas y de clase y en un grado algo mayor en términos de orientaciones ideológicas generales y del problema de la autonomía regional. La misma investigación indicaba igualmente que se daba una fuerte conexión entre los cleavages más importantes ${ }^{3}$. Enmarcada en una perspectiva comparada, la polarización en España parecía ser algo menor que en Finlandia o Italia, pero definitivamente mayor de la que se encuentra en los países caracterizados por lo que Sartori ha denominado «pluralismo moderado» ${ }^{4}$. Con independencia de la polarización, la estabilidad del nuevo régimen es incluso más problemática por la existencia de sistemas de partidos propios en algunos niveles regionales en los cuales las fuerzas nacionalistas desempeñan un papel central. Su presencia sirve para mantener vivo el problema fundamental de la estructura del Estado español.

El realineamiento del sistema de partidos en 1982, con la desaparición de UCD y el debilitamiento del PCE en el ala izquierda del espectro ideológico, ha sido interpretada por algunos observadores como avances en la dirección de una mayor polarización. Esta es una deducción plausible; sin embargo, los resultados de las elecciones no explican directamente la situación. Los resultados electorales no pueden por sí mismos explicarnos si el aumento de AP y el crecimiento del PSOE estuvieron acompañados por un incremento o descenso de la homogeneidad interna de los dos grupos de electores con respecto de los principales cleavages, de la misma manera que tampoco pueden decirnos mucho sobre la distancia política global que separa ambos grupos. La respuesta a la cuestión de si ha habido un incremento de la polarización en el nivel de masas sólo puede encontrarse en datos sobre las actitudes de los votantes y especialmente de aquellos electores que, al cambiar su opción de voto en 1982, contribuyeron decisivamente al profundo realineamiento ocurrido en ese año. Existe una razón adicional para tratar de ir más allá de los resultados electorales. La polarización puede haberse visto incrementada incluso en zonas de España en las que el cambio electoral ha sido menos llamativo. A diferencia de lo que ocurrió a nivel nacional, las elecciones de 1982 no significaron un realineamiento brusco del sistema de partidos en el País Vasco y Cataluña. Efectivamente, UCD experi-

${ }^{2}$ Hemos traducido por «tensión», en unos casos y «escisión» en otros el término inglés cleavage. Cuando la equivalencia de este último con aquellos términos no es absoluta, utilizamos directamente el vocablo inglés.

${ }^{3}$ Richard Gunther, Giacomo Sani y Goldie Shabad, «Party Strategies and Mass Cleavages in the 1979 Spanish Election», en World Affaires, 143,2, otoño 1980, págs. 163-216. Existe traducción al castellano: «Estrategia de los partidos y escisiones de masas en las elecciones parlamentarias de 1979», en Revista de Derecho Político, 11, 1981.

${ }^{4}$ Giacomo Sani y Giovanni Sartori, «Polarization Fragmentation and Competition in Western Democracies», en Hans Daalder y Peter Mair (eds.), Western European Party Systems: Continuity and Change, Beverly Hills, Sage, 1983, págs. 307-340. Existe traducción al castellano: «Polarización, fragmentación y competición en las democracias occidentales», en Revista del Departamento de Derecho Político, 7, 1980, págs. 7-37. 
mentó, como en cualquier otra zona, una aplastante derrota, pero en ninguna de las dos regiones había sido un partido mayoritario antes de las elecciones de 1982. De manera similar, el PSOE obtuvo un éxito considerable, que no fue igualado por ningún otro partido.

Sin embargo, a pesar de estas similitudes en los cambios electorales producidos en el sistema de partidos nacional y regional, se podría sostener que las. elecciones de 1982, en el País Vasco y Cataluña, reflejaron más continuidad que. cambio. A diferencia de lo ocurrido a escala nacional, el centro del espectro político en ambas regiones se mantuvo ocupado por el PNV y por CiU. Además, no tuvo lugar ningún cambio importante en la especificidad de los dos sistemas. regionales de partidos entre las elecciones generales de 1979 y las de 1982: el PNV y CiU incrementaron su fuerza electoral y los partidos radicales abertza-les, Herri Batasuna y Euskadiko Ezkerra, mantuvieron sus anteriores niveles de apoyo, incluso después de la consecución de la autonomía regional. En suma, después de 1982, las principales fuerzas políticas continuaron siendo el PSOE. y CiU, en Cataluña, y el PSOE, PNV y Herri Batasuna, en Euskadi. La estabilidad global de los sistemas catalán y vasco no implica necesariamente, sin em-bargo, la estabilidad de las orientaciones políticas de los electores o la ausencia de cambio en el grado de polarización entre los principales grupos de votantes.. La concesión de la autonomía entre las dos elecciones parlamentarias y el debate: todavía presente sobre la creación de un Estado de las autonomías han tenido, probablemente, un impacto considerable en las orientaciones de los electorados: regionales, así como en las actitudes específicas de los votantes de cada una de: las fuerzas políticas. Una vez más, no es posible valoración alguna de los cambios en el nivel de polarización de la política española sin realizar un examen de. las actitudes de los. votantes a través del tiempo.

En este trabajo ofrecemos los resultados de un análisis comparativo de las. actitudes de masas en España en 1979 y 1982 basado en dos extensas encuestas. poselectorales al electorado español ${ }^{5}$. Comenzamos con una breve discusión del. concepto y método utilizados en este estudio (sección 1) y presentamos a conti-nuación la tesis global de nuestro trabajo (sección 2). La sección 3 se ocupa de las cleavages tradicionales: religión, clase social y cuestión regional. Finalmente examinaremos el problema de la polarización en relación a las dimensiones más. explícitamente políticas del conflicto partidista ${ }^{6}$.

${ }^{5}$ El estudio de 1979 fue llevado a cabo por Goldie Shabad, Richard Gunther y Giacomo Sani y fue financiado por la National Science Foundation. El estudio de 1982, en el que se incluyen Juan Linz, José Ramón Montero Gibert y Hans Jurgen Puhle fue posible gracias a la ayuda financiera de la Stiftung Volkswagenwerk. En los dos años, las encuestas poselectorales, con 5.500 casos aproximadamente, fueron llevados a cabo en España por Data, S. A., de Madrid. Las opiniones y conclusiones que se presentan en este trabajo son las de los autores y no reflejan necesariamente las posiciones ni de la NST ni de la VW Foundation.

- Dado el amplio abanico de aspectos actitudinales considerados aquí, nuestro tratamiento de cada uno de ellos es necesariamente breve. Muchos de estos problemas serán analizados por los autores con mayor detalle en posteriores estudios. 


\section{CONCEPTO Y METODO}

El concepto de polarización, tal y como es utilizado aquí, está impregnado de la imagen espacial del lenguaje cotidiano. Decimos que dos grupos son «polos separados» para indicar que sus actitudes son tan marcadamente distintas que no podrían encontrarse más distantes cada uno del otro. De forma inversa decimos que las posiciones de dos grupos se encuentran muy cerca una de otra para indicar que sus miembros comparten orientaciones comunes. Desde este punto de vista, la similitud de las actitudes no requiere un pleno consenso dentro de cada grupo; exige simplemente que las divisiones internas sean más o menos paralelas. Cuando esto ocurre, los dos grupos son, en efecto, indistinguibles el uno del otro. La mayoría de los grupos no son ni. totalmente diferentes ni absolutamente similares, y establecer el grado de polarización significa explorar la distancia que los separa. Un conjunto de medidas tomadas durante un tiempo nos dirán si los grupos son divergentes o convergentes y, por ello, si el sistema se dirige hacia una configuración «moderada» o «polarizada».

Los cambios en los niveles de polarización pueden provenir de fuentes diversas. La primera es el cambio en las posiciones que sostienen los miembros de los grupos. La polarización podría incrementarse si, como resultado de cambios individuales en al menos un grupo, se produce una neta divergencia global entre los dos. Aunque esta fuente potencial de polarización es claramente significativa, no es la única. Una segunda posibilidad es que la distancia entre grupos creciera como consecuencia de cambios en su composición. Ello es más probable que suceda cuando aquéllos se expanden (o contraen) notablemente. En - este caso, la entrada de los nuevos miembros (o la salida de los antiguos) puede -alterar de una manera significativa la configuración global de las actitudes de los grupos. Naturalmente, en cualquier situación específica ambas fuentes de polarización deben ser tenidas en cuenta. Pero el punto importante sobre el que hay que insistir aquí es que los cambios en la composición de los grupos pueden causar un incremento en la polarización partidista incluso cuando las actitudes individuales se mantengan invariables.

Una variedad de grupos diferentes podrían ser apropiadamente escogidos, dependiendo de cuál sea el enfoque específico del estudio. Desde la perspectiva -del análisis de los sistemas de partidos competitivos, los grupos más interesantes son aquellos $a$ ) que se encuentran definidos por algún criterio político (típicamente partidista) y b) que representen segmentos relativamente amplios de una sociedad que en el supuesto de que el sector representado sea pequeño, tenga una cierta significación en el sistema político ${ }^{7}$. Las razones que se encuentran detrás de estos criterios son claras. Las divisiones que no se encuentran relacionadas con los alineamientos partidistas podrían ser relevantes desde distintas perspectivas y podrían proveer información de interés sobre una sociedad. isin embargo, no tienen probablemente demasiada importancia en términos del conflicto político. Una sociedad pudiera muy bien encontrarse dividida, incluso profundamente dividida, con respecto de un conjunto de problemas, pero si es-

'? Sobre el concepto de relevancia sistemática y los problemas de su valoración, véase "Sartori, Parties and Party Systems, cap. 5: «Rules for Counting», págs. 121 y sigs. 
tas posiciones diferentes se cruzan a través de los partidos, su impacto tiende probablemente a moderar el conflicto más que ha expandirlo o reforzarlo. Esta línea argumental ha sido aducida muchas veces y no necesita ser repetida aquí.

En el caso de España a final de los años setenta, los criterios anteriores aparecen claramente como la clave de los grupos partidistas del PSOE, UCD y AP y de partidos regionales como el PNV, HB y CiU. Obviamente, ello no significa que los otros grupos sean irrelevantes. Por ejemplo, el PCE ha perdido recientemente terreno y algo de su relevancia en tanto que componente del sistema de partidos. Sin embargo, podría muy bien reconquistar su importancia en un futuro no muy lejano. En cualquier caso, parece claro que la configuración global de los sistemas de partidos nacional y regional en 1979 y en 1982 ha dependido de las distintas fortunas de los partidos anteriormente mencionados. Y de ello se deriva que una estimación de la polarización requiere examinar los cambios habidos a lo largo del tiempo en la «distancia política» que separa a esos grupos.

Podría argumentarse que la definición de polarización en términos de distancia nos compromete con un enfoque que tiene unas determinadas implicaciones metodológicas. Sin embargo, el uso de tales imágenes espaciales no implica necesariamente la adopción de presunciones rígidas sobre la naturaleza del espacio en el que la distancia política es valorada. En primer lugar, pocos analistas, si es que alguno, reivindicarían que la distancia política fuera contemplada de la misma manera que una distancia física. Por otro lado, los datos extraídos de las encuestas previenen que la analogía sea llevada tan lejos. Dicho esto, se podría añadir que los típicos datos a nivel ordinal y nominal pueden producir valoraciones sobre actitudes o sobre la cuestión de la distancia que tienen una importante significación. Además, la experiencia ha demostrado que el uso de otras técnicas de análisis apropiadas para niveles de medición más altos no conducen a resultados diferentes apreciables.

El método usado en este estudio puede ser ilustrado por los datos contenidos en la tabla 1 y en los gráficos de la figura A. Se muestran tres grupos dé distribuciones de frecuencia escogidos con propósitos ilustrativos. El primero de ellos implica dos grupos de votantes de partidos que difieren profundamente acerca de la solución idónea al «problema regional». Resultado que no sorprende, dado que, bajo la etiqueta de «grupo A», se encuentran partidarios de las pequeñas fuerzas regionales de izquierda, mientras que los que forman parte del «grupo B» eran simpatizantes de Fuerza Nueva. El segundo juego de distribuciones hace referencia a la «simpatía» hacia los sindicatos. Aquí los dos grupos (votantes del PSOE y AP en 1982) difieren obviamente el uno del otro, pero no tanto como en nuestro primer ejemplo. Finalmente, el tercer juego de distribuciones ilustra un caso de ausencia casi completa de diferenciación entre los dos grupos partidistas (votantes de UCD y CD en 1979) en relación a la dimensión religiosa. Consideremos ahora brevemente la lógica de alguna de las diferentes medidas y veamos cómo ellas recogen los distintos grados de polarización que caracterizan estos tres juegos de datos.

La primera medida se basa en una comparación de los porcentajes en las distintas casillas de las dos filas. Puede ser denominada como «coincidente» y es computada sumando los porcentajes menores que aparezcan en cada columna y 
dividiéndolos entre 100. La lógica de la medida es muy simple. El porcentaje más pequeño dentro de cada columna nos dice que, con respecto de una categoría de respuesta dada, hay una coincidencia de $x$ puntos. Así, la diferencia entre dos grupos partidistas en la categoría «centralismo» es sobre 73 puntos; en la categoría de autonomía «limitada» es ligeramente menor de tres puntos, etc. La medida puede ser visualizada en la figura $A$, observando la extensión del área sombreada, que presenta precisamente el solapamiento que existe en cada una de las columnas. Añadiendo los valores apropiados, uno por cada columna, y dividiendo entre 100 , se obtiene una medida conveniente, que va de 1 (coincidencia completa) a 0 (separación total entre los grupos). En los tres casos ilustrados, los coeficientes fueron $.27, .57$ y .98 , respectivamente. Resultados que parecen recoger razonablemente bien las diferencias aparentes en las distribuciones. Se podría señalar que la primera medida es insensible tanto al número de casos tenidos en cuenta como al orden de las categorías de respuesta. Estas últimas pueden ser cambiadas de lugar sin que afecte a los resultados. Mientras esta propiedad no es incompatible con el uso de los datos a un nivel alto de medición, se podría preferir volver, cuando se tienen en cuenta datos ordinales, a una de las medidas de asociación apropiadas para este nivel, tales como Gamma o Somer's $D$. Los valores de este último coeficiente para los tres casos ilustrados anteriormente fueron $.66, .36$ y 0 , respectivamente. Aparecen así inversamente relacionados, como resulta lógico, con nuestra primera medida.

Finalmente, dado que la polarización, tal y como ha sido conceptualizada aquí, está relacionada con la noción de distancia, una medida basada en las diferencias entre las medidas, pero que tenga también en cuenta las propiedades de las distribuciones, tiene un atractivo intuitivo, especialmente para escalas de un amplio número de clases, tales como los «termómetros de sentimientos» y las «escalas izquierda-derecha». En este supuesto, la polarización puede ser valorada por medio de un análisis de varianza, esto es, contrastando «entre grupos» con variaciones «dentro de los grupos». En este caso, el coeficiente más apropiado es el estadístico eta, que para el caso ilustrado fue de $.74, .46$ y .01, respectivamente. La ventaja principal de utilizar esta tercera medida de polarización es que su cuadrado puede ser interpretado como la proporción de la varianza total en la distribución global de las actitudes que manifiestan los votantes que pertenecen a uno de los dos grupos.

Toda vez que estas tres medidas están basadas en una lógica diferente y reflejan en là muestra distintas propiedades de las distribuciones en cuestión, no es sorprendente que sus magnitudes absolutas arrojaran las siguientes variaciones:

\section{CASOS ILUSTRATIVOS}

\begin{tabular}{|c|c|c|c|}
\hline & I & II & III \\
\hline Coincidencia $\ldots \ldots \ldots \ldots$ & .27 & .57 & .98 \\
\hline $\begin{array}{llllll}\text { Somer's } D & \ldots & \ldots & \ldots & \ldots & \ldots\end{array}$ & .66 & .36 & 0 \\
\hline $\begin{array}{llllllll}E t a & \ldots & \ldots & \ldots & \ldots & \ldots & \ldots & \ldots\end{array}$ & .74 & .46 & .01 \\
\hline
\end{tabular}


FIGURA A.--llustración de diferentes grados de polarización.

Grupo A Grupo B
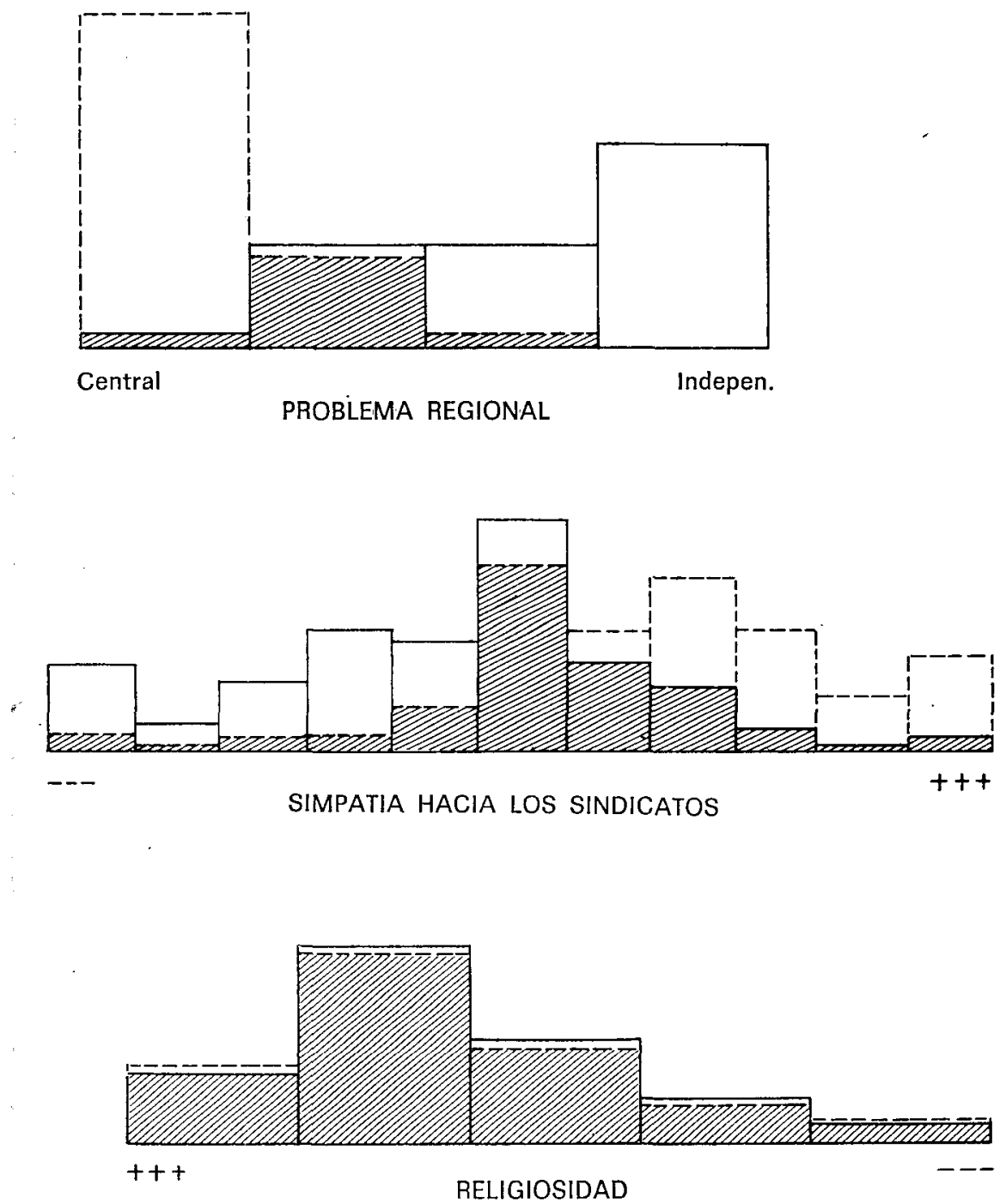
TESIS

Nuestra tesis es que el realineamiento de 1982 en el ámbito nacional produjo un incremento en la distancia política entre los principales grupos partidistas. La tesis a ese nivel se desarrolla como sigue:

1. La base electoral de UCD en 1977 y en 1979 era heterogénea en términos de composición social, actitudes sobre los cleavages más importantes y respecto de las orientaciones políticas generales ${ }^{8}$.

2. Esta heterogeneidad política se reflejaba en la autoubicación de los votantes de UCD en una escala izquierda-derecha. Como se ha demostrado en otra parte, esta distribución tuvo su centro de gravedad hacia la mitad del espectro ideológico; sin embargo, se solapaba considerablemente con el segmento más moderado del PSOE por un lado, y por otro, con los sectores menos conservadores del bloque de Coalición Democrática ${ }^{9}$.

3. Cuando los votantes de UCD abandonaron su partido en 1982, sus opciones electorales siguieron la lógica de la proximidad espacial, esto es, los sectores más progresistas fueron hacia los socialistas, y los elementos más conservadores optaron por el partido de Fraga ${ }^{10}$.

4. Como resultado de estos cambios, la imagen (en términos de orientaciones políticas) de los beneficiarios del colapso de UCD resultó modificada. No obstante, la base de AP resultó más afectada porque el influjo de los antiguos votantes de UCD fue proporcionalmente más alto en el caso de este partido que en el caso del PSOE. Además, los socialistas también se beneficiaron del flujo de votantes que habían abandonado el PCE, lo que produjo algunos efectos compensatorios.

5. La suma de los nuevos sectores de votantes a los ya existentes en el PSOE y AP fue bastante más importante a la hora de determinar la imagen actitudinal de estos grupos que los cambios habidos en las orientaciones políticas al nivel de masas durante el período de 1979-1982.

6. El realineamiento de los votantes en $\mathbf{1 9 8 2}$ hizo el bloque de votantes de AP más moderado respecto de la mayor parte de las orientaciones políticas que tenía el partido en 1979 , mientras que el perfil actitudinal del PSOE se encontró, por el contrario, sólo marginalmente afectado.

7. Sin embargo, como consecuencia de la desaparición de UCD, la distancia total entre los dos grupos principales de votantes de 1982 fue mayor que la que separaba los dos grupos partidistas más importantes en 1979.

8 Juan Linz y otros, Informe sociológico sobre el cambio político en España, 1975-1981, Madrid, Euramérica, 1981; Giacomo Sani, «Partiti e atteggiamenti di massa in Spagna e Italia», en Revista Italiana di Scienza Politica, 2, 1981, págs. 235-279; Gunther Sani y Shabad, «Party Strategies...», cit.

9 Sani, «Partiti e atteggiamenti...», cit., pág. 274.

10 Para una primera exploración de las causas del realineamiento de las elecciones de 1982, véase Richard Gunther, «A Preliminary Analysis of the 1982 Spanish System Realigment», presentado en el Seminario sobre política española, en Bad Homborg, Alemania, 30 de junio-2 de julio de 1983. 
GRAFICO 1.-Autoubicación de los votantes españoles en la escala ideológica izquierda-derecha, 1979 y 1982

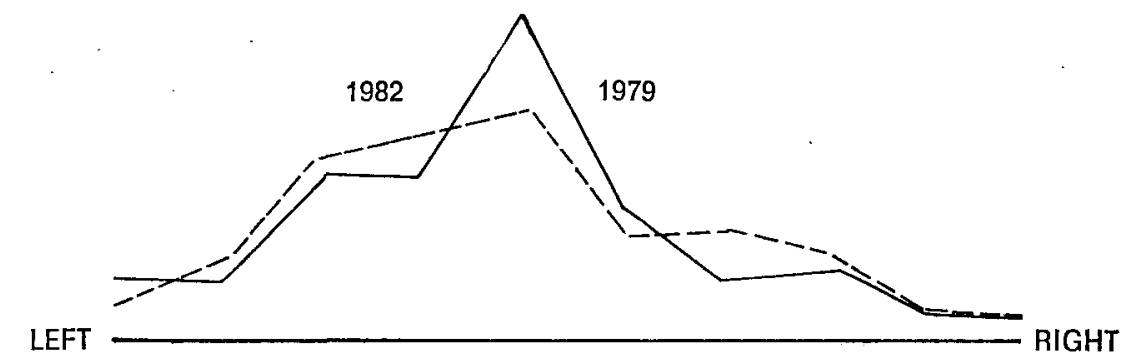

Media $=4,72$

Media $=4,81$

S. D. $=1,94$

$N=4571$

S. D. $=1,98$

$\mathrm{N}=4799$

1979

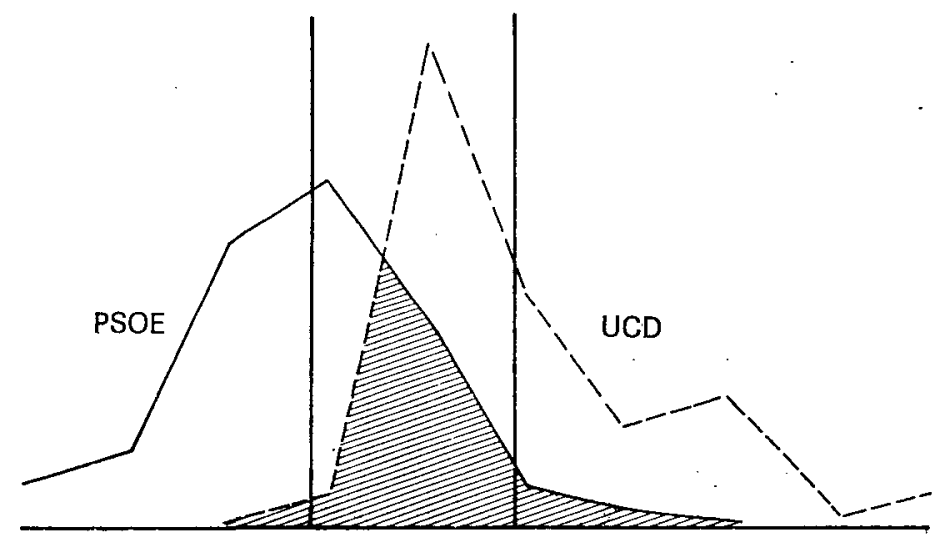

PSOE

$$
\text { Media }=3,87
$$

Media $=5,90$

S. D. $=1,32$

$N=1220$

UCD

S. D. $=1,45$

$N=1412$

1982

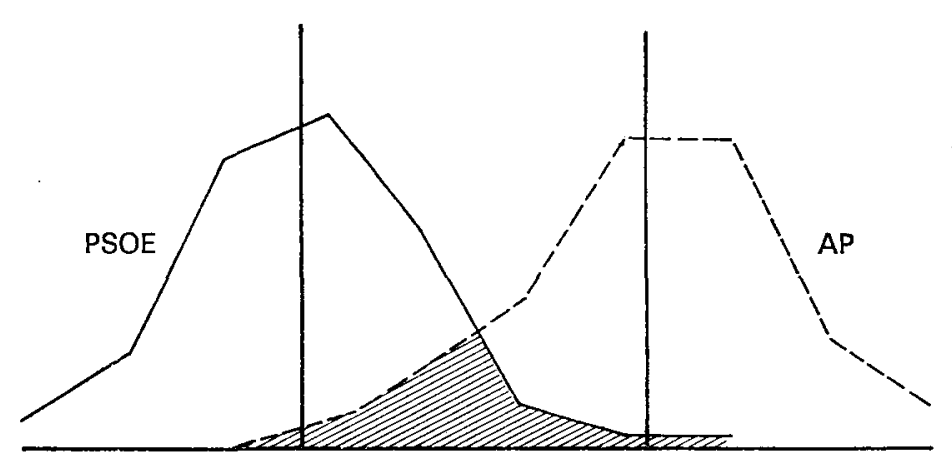

PSOE
AP

$$
\text { Media }=3,80
$$

Media $=7,23$

S. D. $=1,29$

S. D. $=1,32$

$N=1954$

$N=857$ 
¿Hasta qué punto estas propuestas se ajustan a la evidencia? En términos generales, la tesis que acabamos de exponer se apoya en la comparación de las distribuciones izquierda-derecha de los grupos más relevantes de votantes españoles en 1979 y 1982. Como muestra el gráfico 1, la media de autoubicación en la escala del electorado como tal no se ha modificado a lo largo de este período. El centro del espectro se encontraba algo menos poblado en 1982 que en 1979, pero ha habido pocos cambios en la varianza de distribución (3,92 puntos en 1979 y 3,76 puntos en 1982). Claramente, por lo que se refiere al electorado como tal, no ha habido cambios en el grado de polarización. Pero el realineamiento y la emergencia de AP como una fuerza significativa parece haber producido una definida polarización entre los partidos. Como muestra el mismo gráfico 1, las posiciones entre los dos grupos partidistas más numerosos divergieron en mayor medida en 1982 que en 1979. Correspondientemente, la coincidencia entre las dos distribuciones (áreas sombreadas) disminuyó considerablemente. No obstante, mientras «dentro de los grupos» las diferencias siguen siendo considerables, el análisis de estas distribuciones muestra que la proporción de varianza total que corresponde a la diferencia «entre los grupos» se incrementó de .35 en 1979 a .52 en 1982.

\section{TABLA 2}

\section{VOTOS EN 1982 Y 1979 EN EUSKADI Y CATALUÑA}

(En porcentajes)

Euskadi, 1982

\begin{tabular}{|c|c|c|c|c|}
\hline & HB & PNV & PSE & AP-UCD \\
\hline \multicolumn{5}{|l|}{ Voto en Euskadi en 1979 ... ... ... } \\
\hline \multicolumn{5}{|l|}{ Voto en $1979 \ldots \ldots \ldots \ldots$} \\
\hline $\begin{array}{llllllllllll}C D & \ldots & \ldots & \ldots & \ldots & \ldots & \ldots & \ldots & \ldots & \ldots & \ldots\end{array}$ & - & - & 0,6 & 30,8 \\
\hline 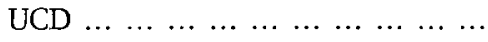 & - & 0,5 & 13,1 & 56,3 \\
\hline $\begin{array}{lllllllllll}\operatorname{PSE} & \ldots & \ldots & \ldots & \ldots & \ldots & \ldots & \ldots & \ldots & \ldots & \ldots\end{array}$ & 0,6 & 0,9 & 35,2 & 1,1 \\
\hline 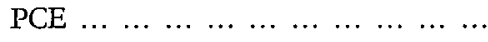 & - & 0,6 & 7,1 & - \\
\hline $\begin{array}{llllllllll}\text { PNV } & \ldots & \ldots & \ldots & \ldots & \ldots & \ldots & \ldots & \ldots & \ldots\end{array}$ & 3,2 & 85,3 & 11,1 & 1,3 \\
\hline 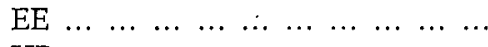 & 5,2 & 1,0 & 1,3 & - \\
\hline $\begin{array}{llllllllllll}\mathrm{HB} & \ldots & \ldots & \ldots & \ldots & \ldots & \ldots & \ldots & \ldots & \ldots & \ldots\end{array}$ & 54,7 & 1,0 & 1,3 & - \\
\hline $\begin{array}{llllllllll}\text { Ineligible } & \ldots & \ldots & \ldots & \ldots & \ldots & \ldots & \ldots & \ldots\end{array}$ & 8,5 & 0,4 & 4,4 & - \\
\hline 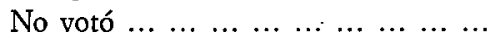 & 15,6 & 9,4 & 21,8 & 3,0 \\
\hline 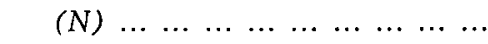 & $(83)$ & $(268)$ & $(220)$ & (46) \\
\hline
\end{tabular}

${ }^{11}$ Esto ha sido demostrado en varios estudios. Véase, por ejemplo, Ronald Inglehart y Hans Klingemann, «Party Identification, Ideological Preferences and Left-Right Dimension», en Ian Budge, Ivor Crewe y Dennis Farlie (eds.), Party Identification and Beyond. Representation of voting and party competition, Nueva York, Wiley, 1976, págs. 225-242, y Sani y Sartory, «Polarization...», cit. 
Cataluña, 1982

\begin{tabular}{|c|c|c|c|}
\hline & $\mathrm{CiU}$ & PSC-PSOE & AP \\
\hline \multicolumn{4}{|l|}{$\begin{array}{l}\text { Voto en Cataluña en } 1979 \ldots \ldots \ldots \\
\text { UCD }\end{array}$} \\
\hline 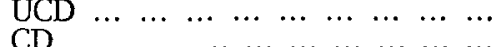 & 17,4 & 16,2 & 51,0 \\
\hline 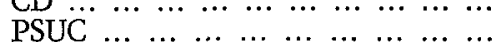 & 04 & $\overline{89}$ & 1,0 \\
\hline 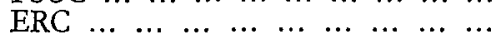 & 2,1 & 1,4 & - \\
\hline 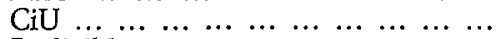 & 59,5 & 3,5 & 3,4 \\
\hline $\begin{array}{lllllllll}\text { Ineligible } & \ldots & \ldots & \ldots & \ldots & \ldots & \ldots & \ldots & \ldots\end{array}$ & 2,7 & 8,7 & 10,0 \\
\hline $\begin{array}{llllllllll}\text { No votó } & \ldots & \cdots & \cdots & \cdots & \cdots & \cdots & \cdots & \cdots\end{array}$ & $\begin{array}{c}5,3 \\
(238)\end{array}$ & 10,9 & $\begin{array}{r}4,5 \\
(120)\end{array}$ \\
\hline & & & \\
\hline
\end{tabular}

GRAFICO 2.-Autoubicación de los votantes en la escala izquierda-derecha en el País Vasco y Cataluña en 1979 y 1982

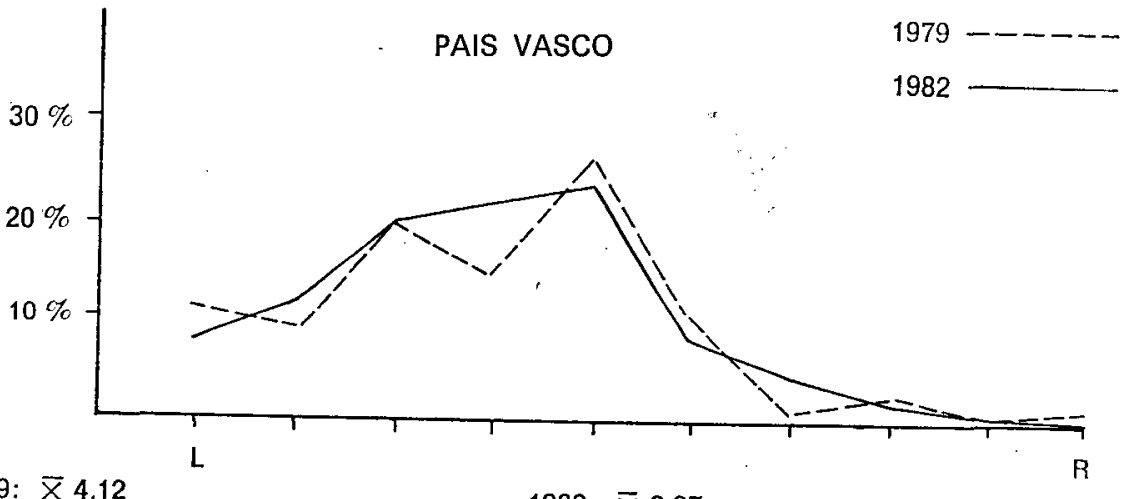

1979: $\bar{x} 4,12$

Sd 1,98

1982: $\overline{\times} 3,97$

Sd 1,70

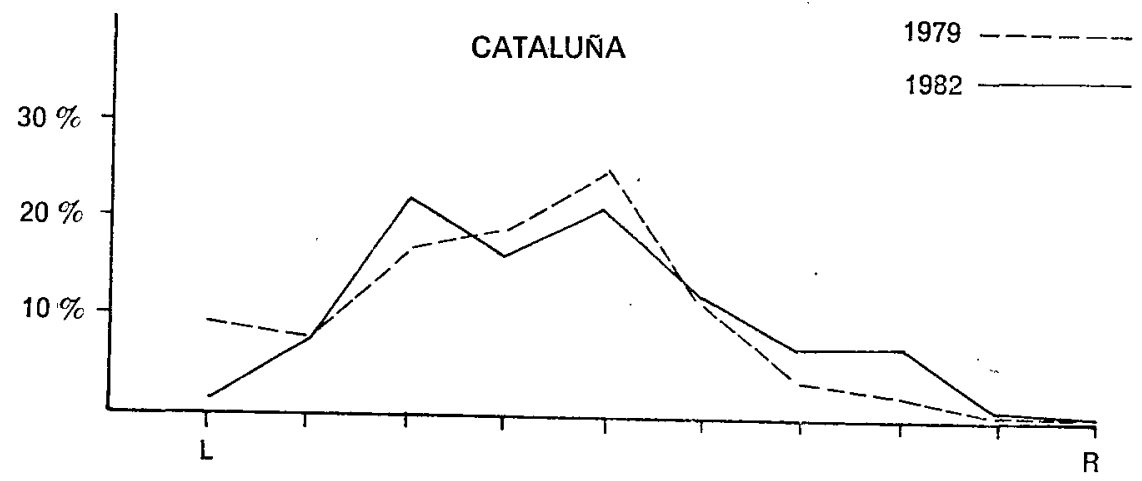

1979: $\bar{x} 4,21$

Sd 1,90

1982: $\bar{x} 4,75$

Sd 1,93 
Por lo que se refiere a los cambios en el grado de polarización dentro del sistema de partidos vasco y catalán, nuestro argumento puede ser formulado como sigue. En estos sistemas, UCD ocupó una posición mucho menos importante que la que ostentaba en el nivel nacional. Por ello, su colapso no trajo consigo un cambio significativo por cuanto hace referencia a los protagonistas políticos. Además, debido a la modesta fuerza de UCD en esas regiones, el influjo de los antiguos votantes centristas no provocó cambios importantes en la composición de los diferentes grupos partidistas. En suma, los cambios en los niveles de polarización motivados por la reestructuración de los grupos partidistas fueron menos relevantes en el País Vasco y Cataluña que en el sistema de partidos nacional. En parte, a causa de ello, la movilización de nuevos votantes en 1982 y de los que se habían abstenido en las anteriores elecciones tendría un considerable impacto sobre la composición de la base electoral de los partidos por los que aquéllos optaron (tabla 2). Finalmente, entre las dos elecciones hubo un cambio importante en el orden institucional del País Vasco y Cataluña. El establecimiento de los respectivos gobiernos regionales autónomos y los problemas y tensiones que la descentralización ha generado (LOAPA, por ejemplo) han debido tener algún impacto sobre las actitudes de los grupos partidistas con respecto de los problemas centro-periferia. A partir de lo que acabamos de exponer se pueden formular las siguientes hipótesis:

1. ${ }^{a} \quad$ El PSOE en el País Vasco y Cataluña se benefició de la entrada de antiguos votantes centristas y comunistas. Dado que los seguidores de UCD eran más numerosos que los partidarios del PCE, especialmente en el País Vasco, el efecto neto de estos cambios electorales fue de un ligero deslizamiento del PSOE a la derecha entre 1972 y 1982. Esto fue probablemente contrarrestado, sin embargo, por el elevado númeto de personas que apoyaron a los socialistas en 1982, pero que no habían votado en 1979.

2. $\quad$ Los dos partidos regionales más importantes (el PNV y CiU) también se beneficiaron de la desaparición de UCD. El contingente de antiguos. votantes de UCD que apoyaron a estos dos partidos fue, no obstante, relativamente pequeño. Además, el PNV y CiU no atrajeron votantes que se movilizaban por primera vez tan ampliamente como lo hizo el PSOE. De esta manera, si las actitudes de estos partidos regionales se modificaron, el cambio fue en una dirección ligeramente a la derecha.

3. ${ }^{\text {a }}$ Por cuanto hace referencia a los partidarios de Herri Batasuna, el grupo más extremista del sistema de partidos vascos, cabe esperar que el importante apoyo obtenido de los votantes jóvenes y de lós abstencionistas de 1979 haya producido algún cambio actitudinal significativo. Por ello, muy probablemente ha habido una ampliación de la distancia entre ellos y los peneuvistas.

4. ${ }^{\mathrm{a}} \quad$ Finalmente, tras la obtención de la autonomía, se podría anticipar un crecimiento de la polarización entre los seguidores de las fuerzas españolas y nacionalistas si a) los votantes del PNV y CiU, a través de un típico proceso de «expectativas crecientes», hubiesen adoptado posiciones más extremas todavía sobre la cuestión regional, y $b$ ) los socia- 
listas se hubieran vuelto más sensibles a las demandas nacionalistas y más hostiles a los intentos de los respectivos gobiernos autónomos, presididos por el PNV y CiU, de imponer una hegemonía política y cultural en las sociedades vasca y catalana. Una polarización mayor, incluso, cabría esperar entre los votantes de Herri Batasuna y el PNV; la frustración de los partidarios de la separatista HB, ante el establecimiento de un gobierno autónomo dirigido por sus enemigos políticos dentro del marco regional de partidos, muy probablemente haya extremado más sus posiciones en relación a la estructura del Estado e incluso que sean más partidarios del uso de la violencia como medio de conseguir la independencia.

¿Hasta qué punto la evidencia corrobora estas suposiciones? En general, las comparaciones de las distribuciones izquierda-derecha de los electorados regionales y de los grupos partidistas principales en el País Vasco y Cataluña en 1979 y 1982 se muestran acordes con nuestro argumento. Como refleja el gráfico 2, la tendencia globalmente considerada de los votantes vascos y catalanes se mantiene a la izquierda del centro. Por lo que se refiere a las diferencias entre los socialistas por un lado y a los partidos regionales moderados por otro, no ha habido cambios significativos si exceptuamos el caso de CiU, cuyo deslizamiento hacia la derecha ha incrementado su distancia respecto del PSOE (gráficos 3 y 4). La única, pero no por ello menos importante, excepción de esta pauta de estabilidad global está constituida por los votantes de Herri Batasuna. Sus tendencias políticas se hicieron más extremistas: en 1982, el 48 por 100 de ellos se autoubicó en la posición más extrema de la izquierda de la escala, mientras que en 1979 sólo lo hizo el 28 por 100 (gráfico 5).

Este cambio ha complicado sustancialmente la distancia entre los dos principales partidos regionales en el País Vasco. Así, aunque, en términos de esta medida general, haya aumentado la polarización entre las fuerzas políticas nacionalistas y españolas, la polarización creció de forma evidente en el País Vasco. En la medida en que los posicionamientos izquierda-derecha están relacionados a las orientaciones en la escala relativas a la cuestión regional, el incremento de la distancia ideológica entre Herri Batasuna y el PNV sugiere que la polarización tuvo lugar también con respecto del cleavage más pronunciado en el seno de la sociedad vasca, es decir, a las divisiones en torno a los problemas centroperiferia.

Los resultados presentados hasta ahora están en concordancia con los argumentos expuestos anteriormente. Estos datos no hablan, sin embargo, demasiado sobre las dimensiones en torno a las cuales se ha incrementado la polarización. Dado el hecho de que lós posicionàmientos en la escala izquierda-derecha son usualmente buenos predictores de actitudes, de evaluaciones de objetos políticos y posiciones sobre problemas, la suposición más razonable es que el crecimiento de la polarización se produjo en algunos de estos aspectos. Pero es posible, incluso muy probable, que mientras las diferencias se hayan profundizado en algunas áreas, en otras permanezcan estables o incluso disminuyan. Nuestros resultados sugieren que éste es el caso. 
GRAFICO 3.-Autoubicación de los votantes de CiU -y PSC-PSOE en la escala izquierda-derecha en 1979 y 1982

\section{CATALUÑA}

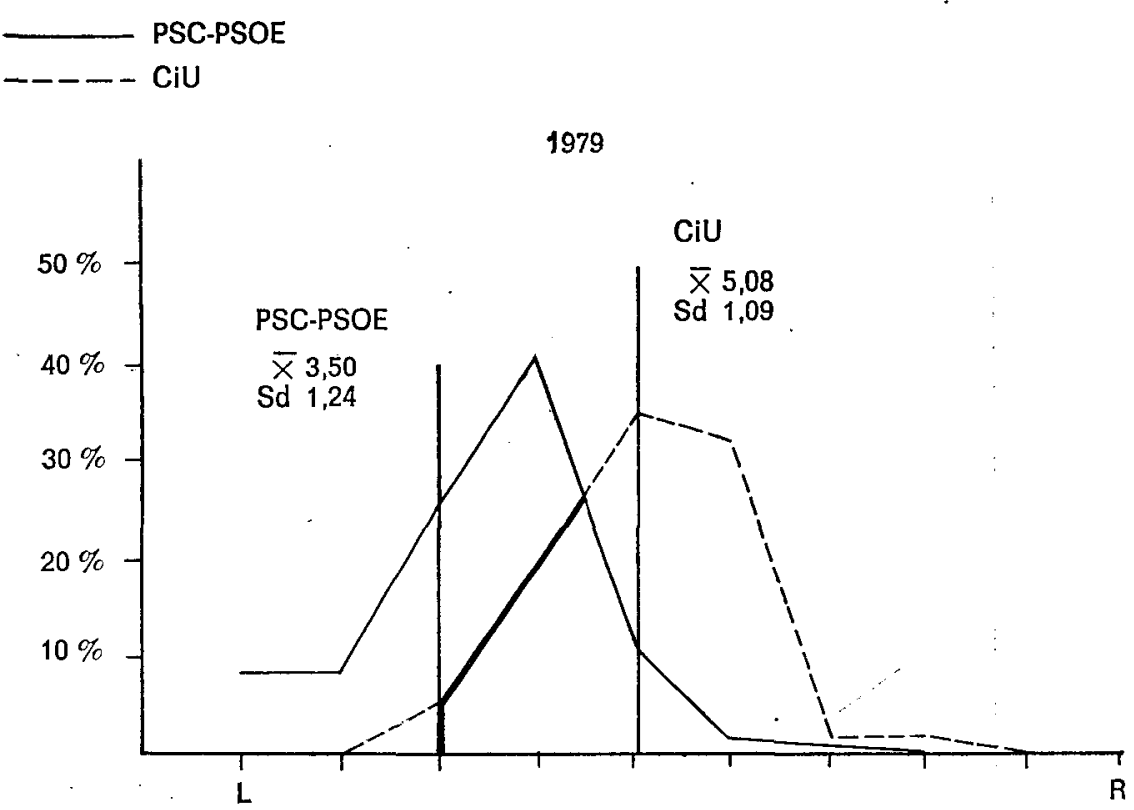

$\mathrm{ETA}=0,47$

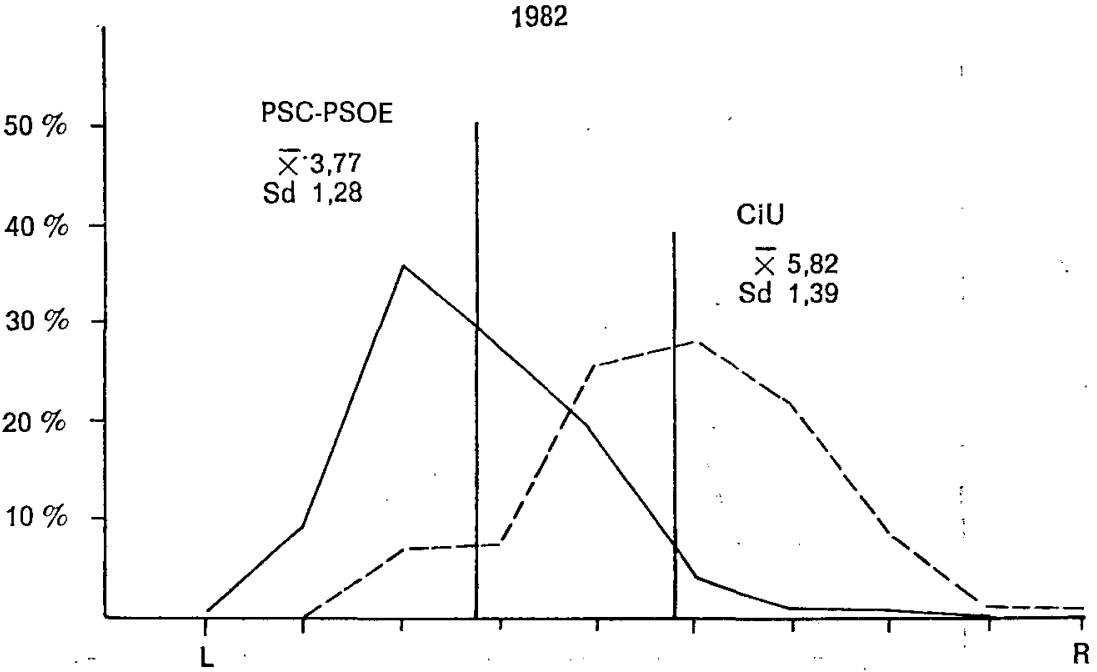

$\mathrm{ETA}=0,60$ 
GRAFICO 4.-Autoubicación de los votantes del PNV y del PSOE en la escala izquierda-derecha en 1979 y 1982

PAIS VASCO

PSOE

PNV

1979

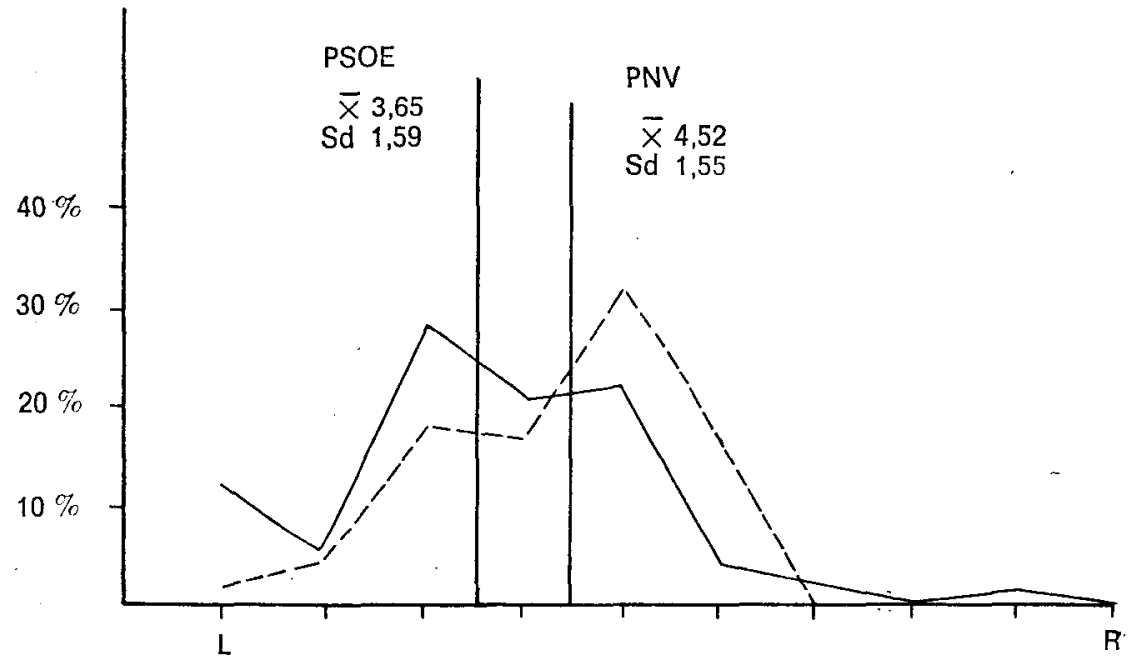

1982

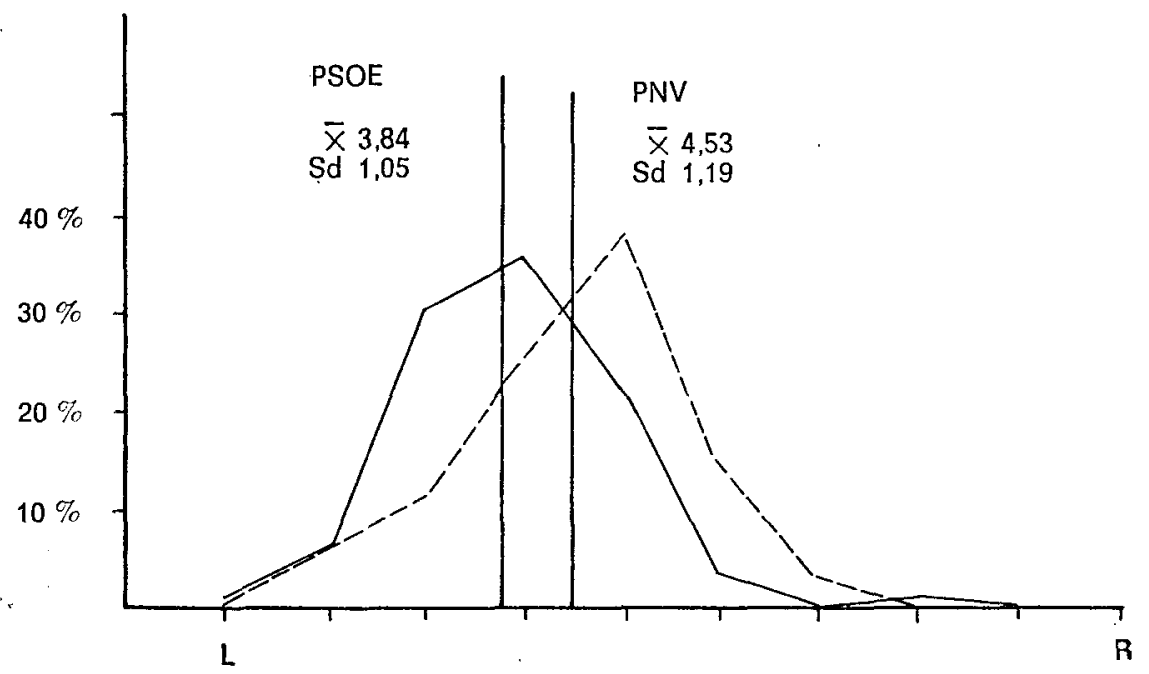


GRAFICO 5.-Autoubicación de los votantes de Herri Batasuna y PNV en la escala izquierda-derecha en 1979-1982

\section{PAIS VASCO}

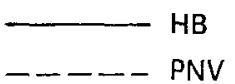

1979
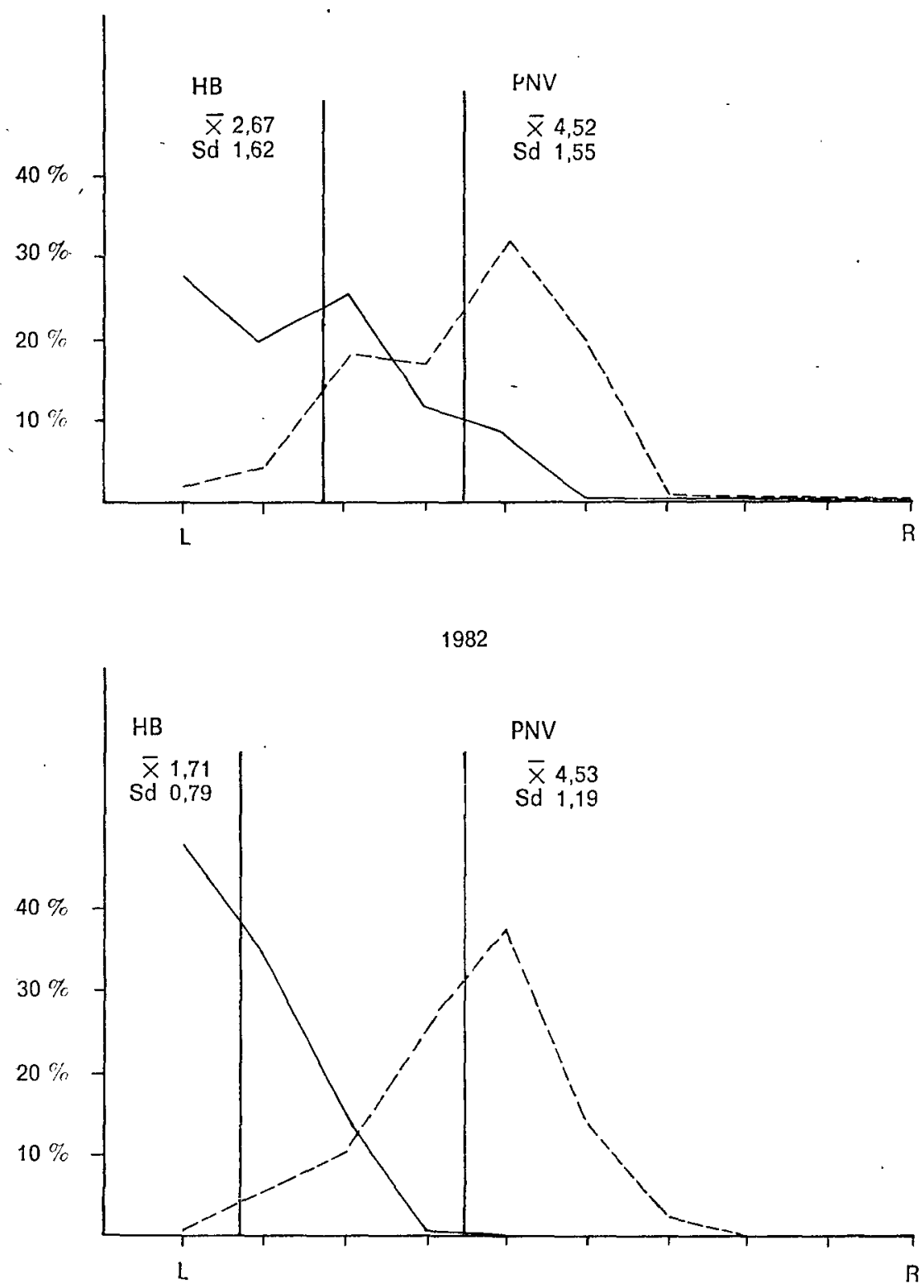


\section{Dimensiones de polarización: los «cleavages» tradicionales}

La hipótesis de una creciente polarización en el sistema de partidos español puede ser enfocada primero en términos de las dimensiones tradicionales de los cleavages: clase, religión y región. En un trabajo anterior hemos analizado un número de indicadores de estas dimensiones y explorado las relaciones entre las posiciones de los votantes sobre aquellos problemas y sus preferencias partidistas en $1979^{12}$. La disponibilidad de indicadores muy similares hace ahora posible examinar si se han producido cambios en la estructura de estas relaciones. Más específicamente, la tarea es determinar hasta qué punto y en qué dirección han cambiado las diferencias entre los principales grupos de votantes en el período 1972-1982.

\section{RELIGION}

Anteriores estudios sobre las actitudes de masas en la España posfranquista han comprobado por lo general la fuerza de la relación entre «religiosidad» y la tendencia política de los votantes. Con independencia de los indicadores específicos utilizados («religiosidad», «sentimientos hacia la Iglesia», «opinión sobre el papel de la Iglesia en la sociedad española», etc.), las opiniones de los entrevistados sobre religión se mostraron muy estrechamente relacionadas con sus orientaciones políticas, sus posiciones en la escala izquierda-derecha y sus opciones de voto. Dicho de otra manera, los electores de los diversos partidos se caracterizan por unas considerables diferencias en términos de la dimensión religiosa. Estas diferencias variaban, sin embargo, según los grupos de votantes considerados. La religiosidad aparece como un buen factor de discriminación en el caso de algunos bloques partidistas, pero no en el caso de otros. Existían diferencias significativas entre los votantes de UCD y del PSOE, entre socialistas y comunistas y otros grupos de la izquierda y entre partidos regionales más moderados y más extremistas en el País Vasco y Cataluña. Sin embargo, en el caso de los grupos que son cruciales para nuestro análisis (votantes de UCD y de CD), las diferencias eran mínimas. En 1979 los electorados de UCD y Coalición Democrática diferían en varios aspectos, pero la «religión» no era uno de ellos. Como muestra la tabla 3, la base electoral de estos dos partidos era poco distinguible una de la otra y se encontraba igualmente distante de los votantes socialistas. Por ello, la división de UCD en dos segmentos, orientados en direcciones políticamente opuestas, no iba probablemente a crear muchas diferencias en la imagen de los partidos que se beneficiaron del viejo electorado centrista. $\mathrm{Y}$ como las distribuciones de 1982 indican, la distancia entre los dos principales grupos partidistas se mantuvo inalterada. Si acaso, hubo un ligero incremento en su proximidad debido al hecho de que en ambos grupos las clases

${ }^{12}$ Gunther, Sani y Shabad, «Party Strategies...», cit.

${ }^{13}$ Linz y otros, Informe sociológico..., cit. 
más extremas («muy buen católico» e «indiferente/ateo») se encuentran ligera-- mente menos pobladas en 1982 que lo estaban en 1979.

TABLA 3

RELIGIOSIDAD POR PARTIDO VOTADO EN 1979 Y 1982

(En porcentajes)

\begin{tabular}{|c|c|c|c|c|c|c|}
\hline & $\begin{array}{l}\text { Muy buen } \\
\text { católico }\end{array}$ & $\begin{array}{c}\text { Católico } \\
\text { practicante }\end{array}$ & $\begin{array}{c}\text { No muy } \\
\text { practicante }\end{array}$ & $\begin{array}{c}\text { No } \\
\text { practicante }\end{array}$ & $\begin{array}{l}\text { Indiferente. } \\
\text { Ateo }\end{array}$ & $\begin{array}{l}\text { Número } \\
\text { de casos }\end{array}$ \\
\hline 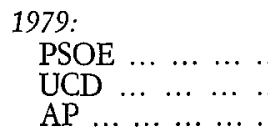 & $\begin{array}{r}4,7 \\
16,7 \\
18,5\end{array}$ & $\begin{array}{l}19,1 \\
45,5 \\
45,4\end{array}$ & $\begin{array}{l}26,1 \\
24,4 \\
23,3\end{array}$ & $\begin{array}{r}27,8 \\
9,6 \\
9,4\end{array}$ & $\begin{array}{r}22,4 \\
3,8 \\
3,4\end{array}$ & $\begin{array}{r}(1344) \\
(1651) \\
(172)\end{array}$ \\
\hline $\begin{array}{l}\text { 1982: } \\
\begin{array}{lllll} & & & & \\
\text { PSOE } & \ldots & \ldots & \ldots \\
\text { AP } & \ldots & \ldots & \ldots & \ldots\end{array} \\
\end{array}$ & $\begin{array}{r}4,8 \\
12,9\end{array}$ & $\begin{array}{l}17,9 \\
49,0\end{array}$ & $\begin{array}{l}30,2 \\
26,1\end{array}$ & $\begin{array}{l}27,5 \\
10,6\end{array}$ & $\begin{array}{r}19,5 \\
1,4\end{array}$ & $\begin{array}{r}(2060) \\
(882)\end{array}$ \\
\hline
\end{tabular}

El análisis de los sentimientos de simpatía/hostilidad de los votantes hacia la Iglesia confirma que han tenido lugar pocos cambios. En una alta proporción, los votantes socialistas continúan mostrando menos simpatía hacia la Iglesia que los votantes de AP, pero la distancia entre los dos grupos no fue mayor que la de socialistas y ucedistas en $1979^{14}$. De hecho, toda vez que la posición anticlerical de la base socialista se suavizó, la polarización parece haber decrecido marginalmente. Es cierto, no obstante, que se mantenían diferencias sustanciales en el perfil de estos dos grupos con respecto al cleavage religioso. Ello se demuestra no sólo por los datos que acaban de ser ofrecidos, sino también por el análisis de las posiciones de los votantes sobre cuestiones tales como la educación pública obligatoria y las subvenciones a las escuelas privadas ${ }^{15}$.

El punto importante, sin embargo, es que las diferencias entre los dos grupos principales no se vio incrementada. Por lo que se refiere al problema que quizá se encuentra más directamente relacionado a la «religiosidad» (el aborto), es imposible evaluar los cambios producidos en la distancia entre grupos porque las posiciones de los votantes sobre este problema no fueron contempladas en la encuesta anterior. En 1982, las posiciones adoptadas por los dos grupo sobre el aborto fueron marcadamente diferentes. Los votantes socialistas y los de AP expresaron opiniones diferentes acerca de si el aborto «debería ser considerado

${ }^{14}$ Las medias en el termómetro de sentimientos fueron las siguientes: en 1979, para. los votantes del PSOE, 4,7 por 100; para los de UCD, 7,3 por 100; en 1982, para los votantes del PSOE, el 5,1 por 100, y para los votantes de AP, el 7,5 por 100 .

${ }^{15}$ Este es uno de los pocos casos en los que parecen haberse producido cambios significativos en las actitudes de los votantes. El porcentaje de votantes socialistas que favorecen la enseñanza pública obligatoria o la no concesión de subvenciones a las escuelas privadas ha. descendido considerablemente. 
un crimen» (AP, el 66 por 100; PSOE, el 28 por 100). También diferían acerca de si el aborto debería ser permitido en casos particulares tales como riesgo de muerte de la madre, malformación del niño, violación o «razones sociales» ${ }^{16}$. No obstante, incluso sobre este problema, las posiciones de los dos grupos no aparecían tan radicalmente yuxtapuesta como uno podría pensar. Entre los votantes de AP hay una minoría que apoya el aborto, al menos en ciertas circunstancias. De igual significación es el hecho de que el electorado del PSOE estuviera profundamente dividido sobre este problema. Y, como resultado de estas divisiones dentro de los dos grupos partidistas, la distancia entre ellos era solamente moderada. En suma, los datos tenidos en cuenta sobre la dimensión religiosa sugieren que las diferencias entre los principales grupos políticos no se agudizaron más en 1982. Como veremos, la conclusión es bastante diferente en el caso de otros cleavages.

\section{CLASE SOCIAL}

Las divisiones entre clases sociales, que habían constituido una notable fuente de conflicto en los años treinta, resultaron en la era posfranquista menos relevantes que entonces a la hora de determinar los alineamientos partidistas ${ }^{17}$. Es cierto que las diferencias de clase no habían desaparecido a mediados y finales de los años setenta, pero un análisis de la composición social de las bases electorales de los partidos indicaba que esas diferencias no eran abrumadoras. Existe un número de razones que explican el debilitamiento de la conexión entre clase y partido: el cambio de la estructura de la sociedad española y en particular la expansión de los estratos intermedios; la moderación en el contenido de clase en los llamamientos que llevan a cabo los partidos tradicionalmente de clase; el relativo éxito de la estrategia catcb-all seguida en las campañas de 1977 y 1979 por las principales fuerzas políticas; la limitada difusión en el electorado de identificaciones profundas de clase, $y$, por último, el hecho de que muchos votantes no valoraran a los partidos como vehículos de los intereses de clase. Como resultado, los grupos políticos que emergieron victoriosos de las elecciones de 1977 y 1979, y especialmente UCD, recibieron apoyo de diferentes estratos sociales, adquiriendo de esta manera una configuración catch-all. Efectivamente, los estratos más bajos estaban representados en mayor número dentro de la base que apoyaba al PSOE que en la que se mostraba partidaria de UCD. Pero el PSOE también tuvo importantes apoyos de las clases medias. Como consecuencia, la composición de los grupos de partidarios de UCD y del PSOE tenía bastante en común. En términos de la ocupación de los entrevistados, los perfiles de estos dos partidos discrepan tan sólo en un grado limitado.

${ }^{16}$ Los porcentajes fueron los siguientes: que se permita el aborto en caso de muerte -o malformación (votantes del PSOE, el 56 por 100; de AP, el 32 por 100); en el supuesto de violación (PSOE, el 31 por $100 ; \mathrm{AP}$, el 16 por 100), y por razones sociales (PSOE el 22 por 100 , y AP, el 4 por 100 ).

${ }_{17}$ Linz y otros, Informe sociológico..., cit.; Gunther, Sani y Shabad, «Party Strategies...», cit. La falta de datos comparables hace imposible llegar a conclusiones definitivas sobre este punto. 
TABLA 4

PERFILES OCUPACIONALES DE LOS PRINCIPALES PARTIDOS EN 1979 Y 1982 *

\begin{tabular}{|c|c|c|c|c|}
\hline & \multicolumn{2}{|c|}{1979} & \multicolumn{2}{|c|}{1982} \\
\hline & PSOE & UCD & PSOE & AP \\
\hline Ocupación de los entrevistados: & & & & \\
\hline 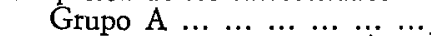 & 5,0 & 9,8 & 4,1 & 20,1 \\
\hline $\begin{array}{lllllll}\text { Grupo } & B & \ldots & \ldots & \ldots & \ldots & \ldots\end{array}$ & 30,0 & 30,3 & 17,6 & 35,5 \\
\hline $\begin{array}{lllllll}\text { Grupo } C & \ldots & \ldots & \ldots & \ldots & \ldots & \ldots\end{array}$ & 11,6 & 14,3 & 14,9 & 16,5 \\
\hline 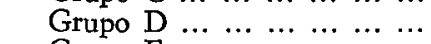 & 28,5 & 18,3 & 32,1 & 15,7 \\
\hline 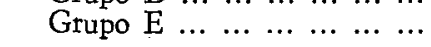 & 24,9 & 27,3 & 31,3 & 12,2 \\
\hline TOTAL $\ldots \ldots \ldots \ldots \ldots$ & $(100)$ & (100) & $(100)$ & $(100)$ \\
\hline
\end{tabular}

\begin{tabular}{|c|c|c|c|c|}
\hline & \multicolumn{2}{|c|}{1979} & \multicolumn{2}{|c|}{1982} \\
\hline & PSOE & UCD & PSOE & AP \\
\hline 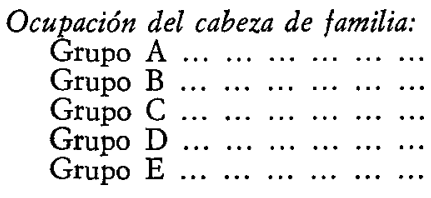 & $\begin{array}{r}3,8 \\
23,6 \\
12,0 \\
33,9 \\
26,7\end{array}$ & $\begin{array}{l}12,0 \\
26,8 \\
12,4 \\
25,4 \\
23,4\end{array}$ & $\begin{array}{r}6,0 \\
12,5 \\
12,8 \\
36,9 \\
31,8\end{array}$ & $\begin{array}{l}26,7 \\
28,5 \\
15,5 \\
15,9 \\
13,4\end{array}$ \\
\hline TOTAL $\ldots \ldots \ldots \ldots$ & $(100)$ & $(100)$ & $(100)$ & $(100)$ \\
\hline
\end{tabular}

* Dada la naturaleza preliminar de este informe, sólo se consignan en la tabla los trabajadores por cuenta ajena. No hay razones, sin embargo, para creer que los resultados habrían sido muy diferentes si se hubieran incluido los trabajadores por cuenta propia. Cada uno de los cinco grupos ocupacionales se componía como sigue:

- Grupo A: directores de empresa, cuadros superiores y funcionarios superiores.

- Grupo B: oficiales, técnicos medios, funcionarios medios y empleados medios.

- Grupo C: agentes, auxiliares, empleados subalternos y suboficiales.

- Grupo D: trabajadores calificados.

- Grupo E: trabajadores' sin calificar.

¿Hasta qué punto ha cambiado la situación? Nuestro análisis indica que el realineamiento de 1982 ha introducido fuertes diferencias en los perfiles ocupacionales de los grupos de votantes de los dos mayores partidos. El peso relativo de ciertas ocupaciones dentro del grupo de votantes socialistas ha cambiado. El porcentaje de electores de los estratos bajos parece haberse incrementado, y así se puede decir que el centro de gravedad del partido ha decrecido. Como muestran las figuras de la tabla 4 , los resultados se mantienen tanto si se considera la ocupación de los entrevistados como la ocupación del cabeza de familia. Además, los datos muestran igualmente que la composición social de AP en 1982 difería significativamente respecto de la de la vieja UCD. Mientras los ucedistas 
en 1979 incluían un número sustancial de votantes de las clases bajas, el bloque de votantes de AP se encuentra escorado hacia los estratos medios y altos. Por esta razón, los perfiles de los dos principales partidos en 1982 son claramente más divergentes que en 1979.

Estos datos forman parte del aspecto «objetivo» de la dimensión de clase. Sin embargo, como numerosos estudios han demostrado, la relación entre preferencia partidista y clase tiende a ser más pronunciada cuando la dimensión subjetiva es tomada en consideración. Por lo que se refiere a las inclinaciones políticas, es la percepción de que la sociedad se encuentra dividida en dos grupos antagónicos y el sentimiento de identificación con uno de ellos, lo que en mayor medida establece una diferencia. El examen de este aspecto de la clase en 1979 y en 1982 confirma la impresión de que se ha producido un crecimiento de la polarización (tabla 5). En nuestra primera encuesta había diferencias en la identificación subjetiva entre los votantes del PSOE y UCD en la dirección que uno podría imaginar. Pero el hecho de que UCD hubiera atraído importantes segmentos de los estratos bajos suaviza considerablemente las diferencias subjetivas de clase entre los dos electorados. En 1982, la identificación subjetiva de clase del electorado socialista era aproximadamente la misma que en 1979. Pero la base electoral de AP se encontraba dividida, casi igualmente, entre las tres clases de identificación y, como consecuencia, el contraste entre los dos grupos fue más marcado.

TABLA 5

IDENTIFICACION SUBJETIVA DE CLASE DE LOS VOTANTES DE LOS PRINCIPALES PARTIDOS, 1979 Y 1982

(En porcentajes)

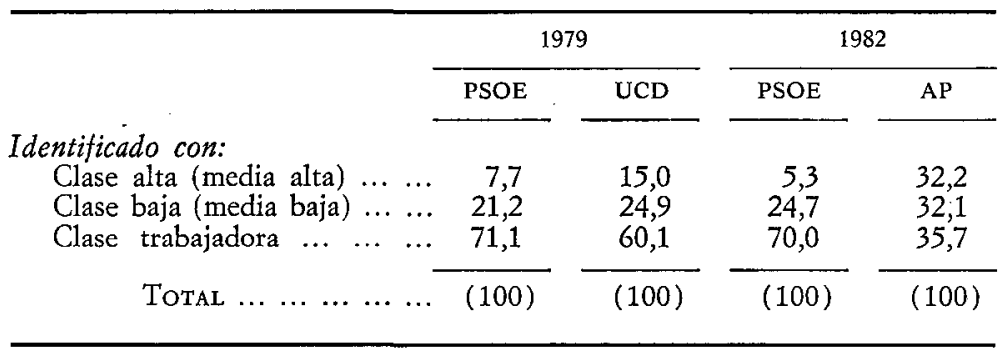

Una evidencia adicional para la hipótesis de que la polarización respecto a la dimensión de clase se ha incrementado se deriva de los datos sobre las actitudes de los votantes hacia las grandes empresas y los sindicatos. Tanto en 1979 como en 1982, a los españoles entrevistados se les preguntó sobre su simpatía u hostilidad hacia los grandes empresarios, utilizando un «termómetro de sentimiento», con una escala de 0 (máxima hostilidad) a 10 (máxima simpatía). Las

is Sani, «Partiti e atteggiamenti...», cit. 
diferencias entre los dos conjuntos de distribuciones mostradas en el gráfico 6 resultan evidentes. En 1982 había una yuxtaposición de los dos principales electorados mucho más pronunciada de la que se produjo tres años y medio antes; varios aspectos del cambio en estas distribuciones merecen la pena ser explorados (por ejemplo, un descenso en la proporción de votantes del PSOE muy hostiles a los grandes empresarios). Estos y otros aspectos serán analizados en posteriores y más detalladas investigaciones. Aquí nos centraremos sólo en la importante disminución experimentada en los solapamientos del segundo juego de distribuciones comparado con el primero y en el correspondiente incremento del valor del coeficiente eta (de .29 en los datos de 1979 a .48 en los de 1982). En el caso de las evaluaciones de los votantes sobre los sindicatos, la comparación no puede ser hecha directamente en términos de distribución a causa de la diferente formalización de la pregunta. No obstante, también en este caso se observa un incremento paralelo entre las diferencias de los dos principales electorados (eta 33 en 1979 a .43 en 1982).

De esta manera, la conclusión que se puede trazar con respecto de la dimensión de clase es muy diferente de la que se obtuvo sobre la dimensión religiosa. Con respecto de esta última, nuestros datos sugieren que las líneas divisorias no habían cambiado apreciablemente. $\mathrm{Ni}$ en términos de religiosidad ni en términos de sentimientos hacia la Iglesia había diferencias entre los dos bloques principales de votantes en 1982 y en 1979. Con respecto al cleavage de clase, la polarización parece, sin embargo, haberse incrementado sustancialmente. Esto es verdad en términos de la composición social de la base electoral de los partidos, además de en relación a la identificación subjetiva de clases. Se ha demostrado, asimismo, que existen cambios paralelos con respecto de los sentimientos hacia los grupos - sindicatos y empresas - que tradicionalmente han simbolizado los polos opuestos del conflicto de clases.

\section{LA CUESTION REGIONAL}

Las investigaciones sobre el nuevo sistema de partidos ha demostrado que de los tres cleavages tradicionales, el que ha producido más división en la política española es el problema regional. Fue, de igual manera, el factor potencialmente más desestabilizador del nuevo régimen, dada la existencia de sistemas de partidos regionales específicos en los que las fuerzas nacionalistas desafiaban directa o indirectamente la misma existencia del Estado español: la importancia de esta tensión fue más aparente en el País Vasco y Cataluña, pero no estuvo limitada en ningún caso a estas dos regiones. La tensión centro-periferia fue también una fuente importante de división partidista en el conjunto del país. ¿Hasta qué punto cambió el nivel de polarización sobre el problema regional

${ }^{19}$ Véase Gunther, Sani y Shabad, Spain After Franco: The Making of a Competitive Party System, caps. 7 y 9, Berkeley, University of California Press, de próxima aparición. Véase también Juan J. Linz, «La crisis de un Estado unitario, nacionalismos periféricos y regionalismos», en La España de las autonomias: pasado, presente y futuro, t. II, Madrid, Espasa-Calpe, 1981; Manuel García Ferrando, Regionalismo y autonomía en España, 19761979, Madrid, Centro de Investigaciones Sociológicas, 1982. 
desde 1979? ¿La entrada en vigor de la autonomía redujo o exacerbó las tensiones sobre este problema? ¿Hay tendencias paralelas en los sistemas de partidos nacional y regional?

\section{GRAFICO 6.--Simpatía/Hostilidad de los votantes del PSOE, UCD y AP} hacia los grandes empresarios

\section{Porcentaje votantes}

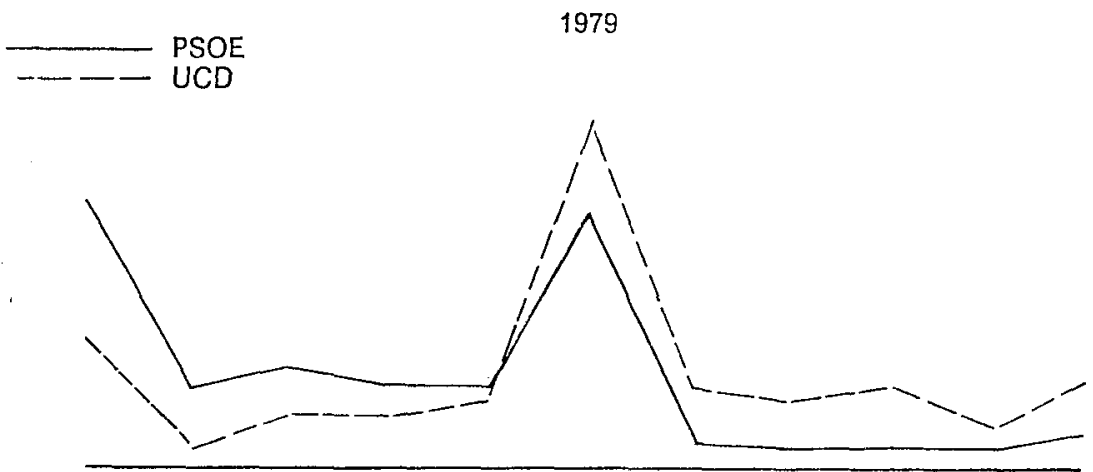

Hostilidad

Simpatía

Porcentaje votantes

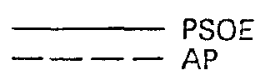

1982

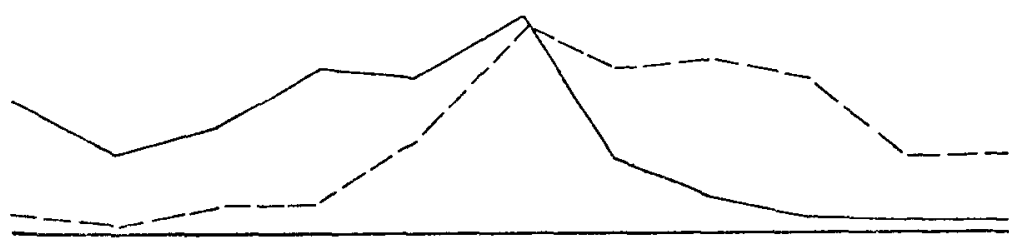

Hostilidad

Simpatía

Sobre la base de un cuestionario idéntico relativo a soluciones alternativas, en 1979 y 1982, al problema regional, los votantes españoles pueden ser clasificados en cuatro grupos: aquellos que prefieren el «centralismo», la «autonomía limitada», la «autonomía amplia» y la «independencia». La comparación de estas clasificaciones entre nuestras dos encuestas indica que prácticamente no hubo cambio en las orientaciones: la «autonomía limitada» continúa siendo la

${ }^{20}$ Para una discusión de las diferencias entre el sistema de partidos vasco y catalán, véase Gunther, Sani y Shabad, Spain After Franco..., cit., cap. 9.

${ }^{21}$ En las encuestas de 1979 y 1982, a los entrevistados en el País Vasco y Cataluña se les preguntó si se sentían «sólo españoles», «más españoles que vacos o (catalanes)», «igualmente españoles y vascos», «más vascos que españoles» o «sólo vascos (o catalanes)». 
fórmula más frecuentemente preferida por el electorado español (sobre el 50 por 100), ligeramente menos de un tercio de los votantes continuaron a favor de un régimen centralizado y sólo una pequeña minoría apoyaba la noción de independencia.

El escaso cambio que ofrecen estos datos indica que los votantes se alejaban de las opciones más extremas; un indicador, quizá, de la creciente aceptación de los Estatutos de Autonomía que han sido aprobados los últimos años. No obstante, el cambio era tan reducido, que las diferencias entre las respuestas dadas en 1979 y en 1982 podrían ser consecuencia de errores en el método de muestreo u otros de naturaleza similar. Cuando se dirige la atención, sin embargo, a los diferentes grupos partidistas a nivel nacional, se encuentra que el colapso de UCD se tradujo en una profundización de las diferencias actitudinales entre los dos principales bloques de votantes que surgieron en 1982. Como muestra claramente la tabla 6 , las orientaciones de los votantes de AP y de los votantes socialistas en 1982, aparecían marcadamente más yuxtapuestas que las de los electores de UCD y PSOE en 1979. Las mayores diferencias resultan ser el incremento de la preferencia entre los electores de AP por la solución centralista, mientras que los votantes socialistas tienden a preferir la solución de la «autonomía limitada».

TABLA 6

PREFERENCIA POR DIFERENTES SOLUCIONES A LA «CUESTION REGIONAL», SEGUN VOTO, EN 1979 Y 1982

(En porcentajes)

\begin{tabular}{|c|c|c|c|c|c|}
\hline & Centralismo & $\begin{array}{l}\text { Autonomía } \\
\text { limitada }\end{array}$ & $\begin{array}{c}\text { Autonomía } \\
\text { amplia }\end{array}$ & $\begin{array}{l}\text { Indepen- } \\
\text { dencia }\end{array}$ & $(N)$ \\
\hline \multicolumn{6}{|l|}{ Votantes en 1979: } \\
\hline $\begin{array}{lllllll}\text { PSOE } & \ldots & \ldots & \ldots & \ldots\end{array}$ & 17,7 & 66,6 & 10,5 & 5,0 & (1284) \\
\hline $\begin{array}{llllll}\mathrm{UCD} & \ldots & \ldots & \ldots & \ldots & \ldots\end{array}$ & 49,0 & 46,6 & 3,6 & 0,8 & $(1528)$ \\
\hline 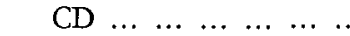 & 64,8 & 30,9 & 3,5 & 0,9 & $(164)$ \\
\hline $\begin{array}{ccccccc}\text { All } & \ldots & \ldots & \ldots & \ldots & \ldots\end{array}$ & 32,8 & 51,4 & 9,4 & 6,4 & $(4985)$ \\
\hline \multicolumn{6}{|l|}{ Votantes en 1982: } \\
\hline $\begin{array}{llllll}\text { PSOE } & \ldots & \ldots & \ldots & \ldots\end{array}$ & 18,7 & 63,3 & 15,7 & 2,3 & (1912) \\
\hline $\begin{array}{lllllll}\mathrm{AP} & \ldots & \ldots & \ldots & \ldots & \ldots & \ldots\end{array}$ & 58,9 & 38,5 & 2,3 & 0,3 & $(852)$ \\
\hline $\begin{array}{lllllll}\text { All } & \ldots & \ldots & \ldots & \ldots & \ldots & \ldots\end{array}$ & 30,9 & 52,2 & 12,1 & 4,8 & $(4947)$ \\
\hline
\end{tabular}

En el nivel nacional, el crecimiento de la polarización sobre la cuestión regional es, en gran medida, atribuible por ello al realineamiento del sistema de partidos. ¿Significa esto que, dado que ningún realineamiento comparable tuvo lugar en el País Vasco y Cataluña, ha habido poco cambio de los electorados vascos y catalanes en relación al problema centro-periferia? Nuestros datos indican que las divisiones entre los principales grupos de votantes con respecto a los diferentes aspectos de esta tensión son ahora más profundas.

Algunos estudios previos acerca de las diferencias partidistas en las dos regiones muestran que el sistema de partidos vasco reflejaba divisiones por lo que hace a los problemas centro-periferia en un grado bastante superior a las del sistema de partidos catalán. Esto no sólo se producía por la presencia y la fuerza 
FIGURA Ba.--Identificación nacional subjetiva en el País Vasco según afiliación partidista en 1979 y 1982

PSOE

--- PNV

1979

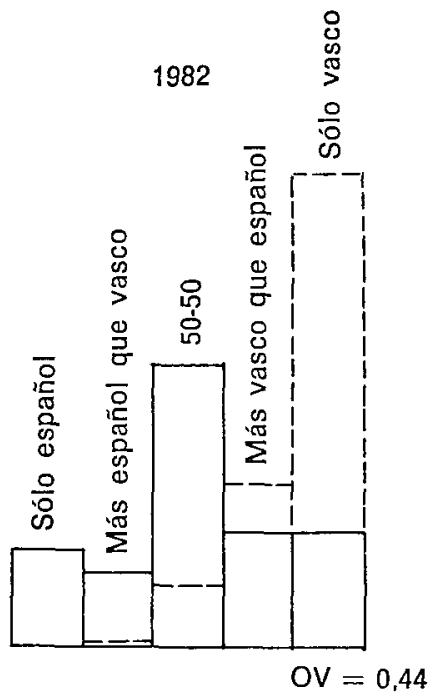

FIGURA Bb.-Preferencias sobre la autonomía en el País Vasco según afiliación partidista en 1979 y 1982
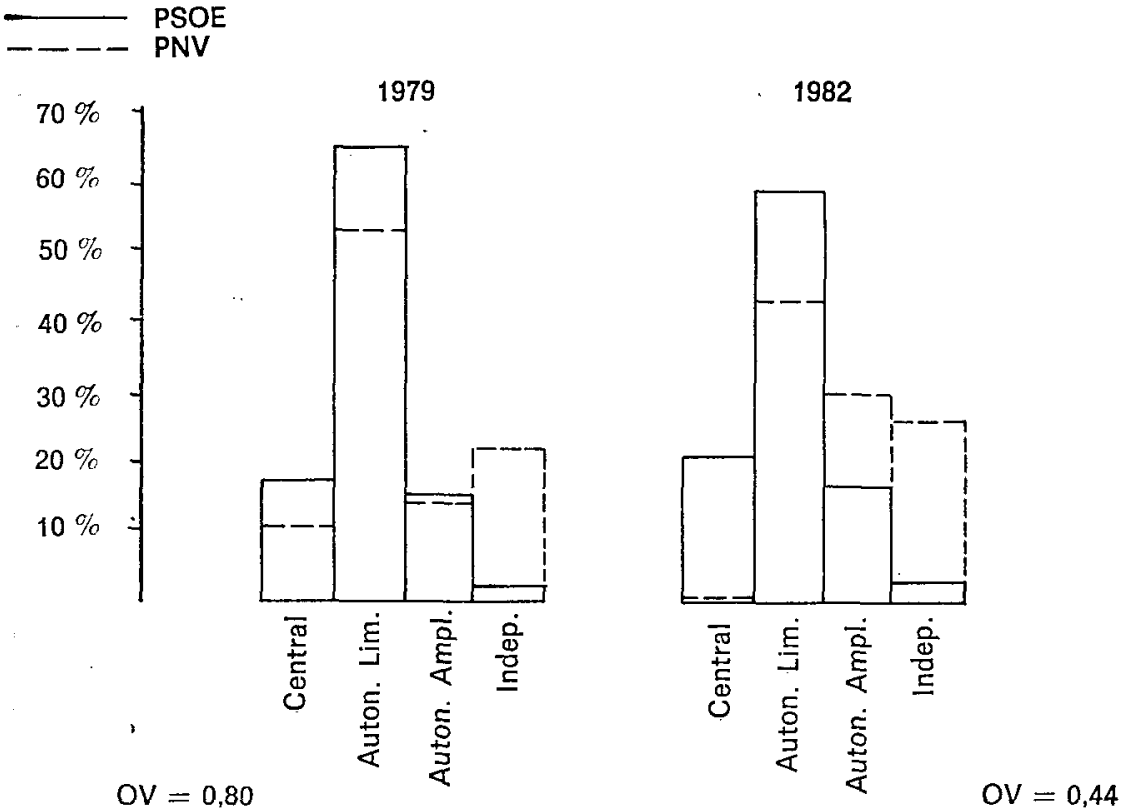
del partido separatista Herri Batasuna, sino también a causa de las diferericias actitudinales entre los votantes del PNV y del PSOE eran mayores que la de los votantes de CiU y del PSC-PSOE. ¿En qué medida fue éste el caso en 1982?

Considerando primero a los votantes del PSOE y del PNV, los dos grupos partidistas se alejaron más en sus autoidentificaciones nacionales y particularmente en sus preferencias hacia la autonomía (véase figura $\mathrm{B} a+b$ ). Incluso aunque en 1982 los votantes socialistas se sentían más vascos y menos españoles que en 1979, el cambio entre peneuvistas hacia una identificación primaria, o exclusiva con el grupo regional, fue inclusive más importante, reflejando un cambio similar en el electorado vasco. Los socialistas presentan poco cambio en sus posiciones sobre la autonomía, excepto por una preferencia ligeramente mayor por el centralismo en 1982. Durante el mismo período, los seguidores del PNV se mostraron mucho más favorablemente dispuestos a una extensa autonomía y, en menor grado, a la independencia.

$\mathrm{Ha}$ habido, sin embargo, una reducción perceptible de la distancia entre los dos electorados con respecto a sus sentimientos hacia ETA. En la misma medida que el electorado vasco se sintió más hostil hacia ETA, lo hicieron los peneuvistas, acercándose de esta forma a los votantes socialistas: en 1982, el 51 por 100 se autoubicaba en el punto más negativo del termómetro de sentimientos, comparado con sólo el 32 por 100 en 1979.

Al margen de aspectos persistentes y básicos de la cuestión regional, como son las preferencias sobre la estructura del Estado y los sentimientos sobre la diferenciación nacional que ahora más que antes diferencian a los votantes socialistas de los del PNV, la evolución al respecto desde la obtención de la autonomía ha conducido además a diferencias interpartidistas sustanciales. Cuando se pidió una evaluación sobre el funcionamiento del Gobierno del PNV, por ejemplo, una inmensa mayoría de los partidarios del PNV, no de forma sorprendente, lo valora muy positivamente; sólo uno de cada tres votantes socialistas hizo lo mismo (tabla 7). Relacionadas con estas diferentes evaluaciones se encontraban los 29 puntos porcentuales entre la percepción de ambos grupos sobre cómo la autonomía había mejorado la vida cotidiana (90 por 100 del PNV frente al 60 por 100 del PSOE). Pero el nuevo problema que más nítidamente dividía a los votantes del PNV de los del PSOE era la LOAPA (Ley Orgánica parạ la Armonización del Proceso Autonómico). El 84 por 100 de los partidarios del PNV creía que la LOAPA limitaría la autonomía, comparado con el

TABLA 7

VALORACION DEL FUNCIONAMIENTO DEL GOBIERNO AUTONOMO VASCO SEGUN LOS VOTANTES DEL PNV Y DEL PSOE

(En porcentajes)

\begin{tabular}{|c|c|c|c|c|c|c|}
\hline & $\begin{array}{l}\text { Muy } \\
\text { bueno }\end{array}$ & Bueno & $\begin{array}{l}\text { Ni bueno } \\
\text { ni malo }\end{array}$ & Mediocre & $\begin{array}{l}\text { Muy } \\
\text { malo }\end{array}$ & $(\mathrm{N})$ \\
\hline Votantes PNV ... ... ... & 31,6 & 52,3 & 13,4 & 2,1 & 0,6 & (236) \\
\hline Votantes PSOE $\ldots$ & 0,9 & 28,5 & 34,7 & 26,9 & 9,0 & (180) \\
\hline Total regional $\ldots \ldots \ldots$ & 13,3 & 29,1 & 28,7 & 21,3 & 10,7 & (788) \\
\hline
\end{tabular}


43 por 100 de los socialistas. Una proporción similar de los primeros estaba contra la LOAPA; sólo el 33 por 100 de los últimos la desaprobaba, y un 60 por 100 decía no tener opinión.

La LOAPA y sus efectos sobre la autonomía regional serán, sin duda, la fuente más importante de conflicto entre los dos partidos principales en el País Vasco y entre el Gobierno del PNV en el País Vasco y el Gobierno socialista en Madrid. La sentencia del Tribunal Constitucional, en el verano de 1983, sobre la LOAPA no acabará probablemente con la controversia.

La polarización del sistema de partidos vasco sobre el problema regional no fue sólo el resultado de la división entre peneuvistas y socialistas (o votantes de AP). Los partidarios de los principales partidos nacionalistas vascos, el PNV y Herri Batasuna, estaban más polarizados en 1982 que los del PNV y del PSOE, y se encontraban más divididos entre ellos que en 1979. Una de las pocas excepciones de estas pautas hace referencia a un aspecto del problema regional sobre el que los partidarios de Herri Batasuna y del PNV de origen vasco iban con toda gran probabilidad a coincidir era la autoidentificación nacional: como la figura $\mathrm{C} a$ indica, ambos grupos se inclinaron (en un grado similar) en la dirección de una identificación exclusiva con el grupo regional. Con respecto de las preferencias sobre la autonomía, las actitudes hacia ETA, la valoración sobre la eficacia del Gobierno autónomo y el impacto de la autonomía en la vida cotidiana, los votantes de HB y del PNV se encontraban, sin embargo, profundamente divididos. La creciente distancia entre ambos en relación a la autonomía, como indica la figura $\mathrm{C} b$, es casi enteramente debida al incremento del número de partidarios de $\mathrm{HB}$ que mantenían posiciones extremistas; mientras que en 1979, el 36 por 100 favoreció la autonomía limitada o amplia y el 61 por 100 era independentista, las proporciones respectivas eran el 15 y 84 por 100 en 1982. No inesperadamente, dadas las posiciones maximalistas de los partidarios de HB, sólo el 33 por 100 consideraba que la autonomía había tenido un impacto beneficioso en la sociedad vasca. Por otra parte, el incremento del nivel de polarización por lo que se refiere a ETA fue debido a la creciente hostilidad hacia esta organización entre los peneuvistas. El 58 por 100 de los partidarios de $\mathrm{HB}$ en ambos años mantenía una actitud positiva hacia ETA, y sólo dos de cada diez se mostraban en contra. Pero nada indica mejor la distancia política y el antagonismo entre los dos grupos que contrastar sus puntos de vista sobre el Gobierno autónomo. Sólo el 3 por 100 de los partidarios de HB hace una valoración positiva de su funcionamiento (véase tabla 8).

TABla 8

VALORACION DEL FUNCIONAMIENTO DEL GOBIERNO AUTONOMO VASCO SEGUN LOS VOTANTES DEL PNV Y DE HB

(En porcentajes)

\begin{tabular}{|c|c|c|c|c|c|c|}
\hline & $\begin{array}{c}\text { Muy } \\
\text { bueno }\end{array}$ & Bueno & $\begin{array}{c}\text { Ni bueno } \\
\text { ni malo }\end{array}$ & Mediocre & $\begin{array}{l}\text { Muy } \\
\text { malo }\end{array}$ & (N) \\
\hline $\begin{array}{lllll}\text { Votantes } \mathrm{PNV} & \ldots & \ldots & \ldots \\
\text { Votantes } \mathrm{HB} & \ldots & \ldots & \ldots \\
\text { Total regional } & \ldots & \ldots & \ldots\end{array}$ & $\frac{31,6}{10,3}$ & $\begin{array}{r}52,3 \\
3,1 \\
29,1\end{array}$ & $\begin{array}{l}13,4 \\
17,8 \\
28,7\end{array}$ & $\begin{array}{r}2,1 \\
40,4 \\
21,3\end{array}$ & $\begin{array}{r}0,6 \\
38,8 \\
10,7\end{array}$ & $\begin{array}{r}(236) \\
(72) \\
(788)\end{array}$ \\
\hline
\end{tabular}


FIGURA Ca.-Identificación nacional subjetiva de los votantes del PNV y HB en 1979 y 1982
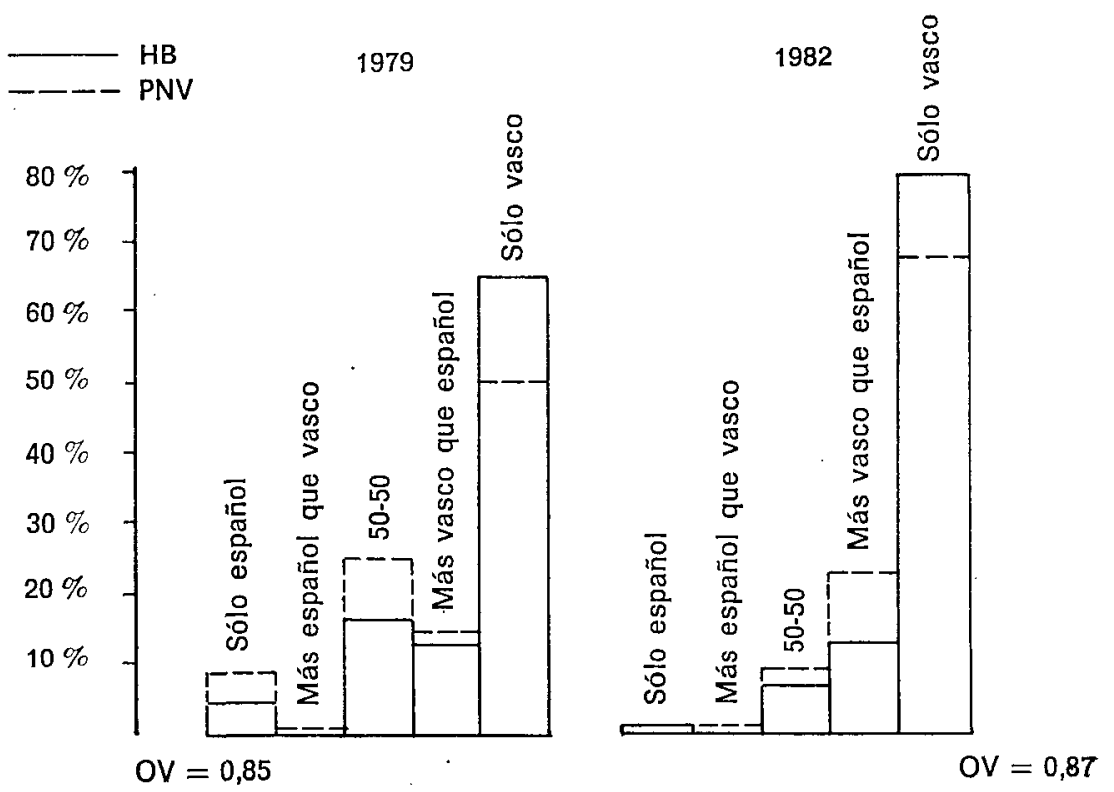

FIGURA Cb.-Preferencias hacia la autonomía entre los votantes del PNV y HB en 1979 y 1982
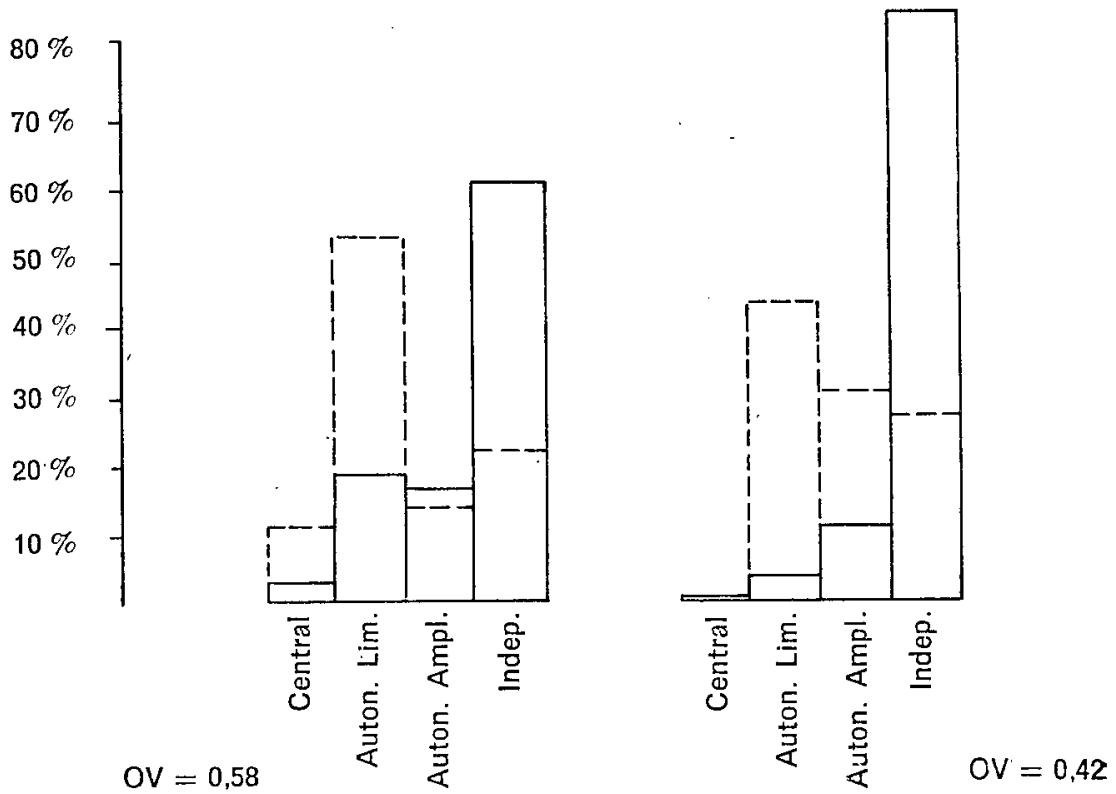
De ahí que el crecimiento de la polarización sỏbre la cuestión regional en el sistema de partidos vasco no se encuentra en cualquier caso reflejado solamente por el incremento de la distancia entre las fuerzas políticas nacionalistas vascas y las españolas. En 1982, más que en 1979, se manifestó además en la profunda separación entre los dos principales partidos nacionalistas. La concesión de la autonomía ha hecho, en suma, a los partidarios de HB más «antisistema» que antes.

Al no haber organizaciones nacionalistas radicales importantes en el sistema de partidos catalán, el conflicto sobre los problemas centro-periferia se debe principalmente a la división de opinión entre CiU y PSC-PSOE. En la mayoría de los casos, los resultados sugieren que desde 1979 ha tenido lugar un ligero incremento del alcance de las diferencias actitudinales.entre los dos principales grupos partidistas. Ello indica, al mismo tiempo, que los seguidores de Convergencia y del PSC-PSOE se diferenciaban bastante menos entre sí que los peneuvistas y socialistas vascos. Existen diversas explicaciones del menor grado de polarización sobre el problema regional en Cataluña en 1982, así como en 1979. Primero, la opinión pública acerca de este problema es más moderada que en el País Vasco. La ausencia de una minoría importante de independentistas se refleja en la insignificancia de las fuerzas extremistas de carácter nacionalista similares a HB. La competencia electoral entre HB y el PNV por los votos ha conducido, además, a una mayor ambigüedad del PNV sobre los problemas centro-periferia, si se le compara tanto con Ezquerra Republicana como con CiU: el 26 por 100 de los partidarios del PNV apoya, por ejemplo, la independencia, mientras sólo el 7 por 100 de CiU mantiene la misma posición. Finalmente, la fusión del PSC con la rama catalana del PSOE en 1978 ha hecho del Partido Socialista en Cataluña un partido mucho más regional, desde un punto de vista organizativo y programático que su equivalente vasco, a la vez que un partido cuyos 1lamamientos a los votantes sobre la base de su regionalismo parecen tener más credibilidad.

En 1982, como en 1979, había una marcada coincidencia en la identificación nacional subjetiva de los votantes de CiU y del PSC-PSOE. Una ligera diferenciación ha tenido lugar, sin embargo, a consecuencia de un incremento de aquellos que se sienten primaria o exclusivamente catalanes entre los partidarios de Convergencia y entre aquellos que se sienten «sólo españoles» o «más español que catalán» entre los socialistas (véase figura $\mathrm{Da}$ ). Un cambio mucho más reseñable tuvo lugar con respecto de las preferencias sobre la estructura del Estado. En 1982 la casi total convergencia entre los dos grupos de votantes de 1979 había desaparecido, como muestra la figura $\mathrm{D} b$; cada uno de ellos era menos favorable a la autonomía limitada y se habían desplazado en direcciones opuestas.

A pesar de la tendencia hacia la polarización de la opinión entre los partidarios de los dos mayores partidos de Cataluña, la importancia de las diferencias sobre estos dos aspectos cruciales de la cuestión regional en ningún caso alcanzaba lo que aparecía entre los seguidores del PNV y los del PSOE, tanto en 1979 como en 1982. Había otros temas, sin embargo, que produjeron desacuerdos profundos entre los votantes del PSC-PSOE y los de CiU en grado similar a los que se encontraron en el País Vasco. Se refieren al funcionamiento del 
FIGURA Da.-Identificación nacional subjetiva de los votantes del CiU y del PSC-PSOE, 1979 y 1982

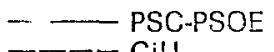

1979

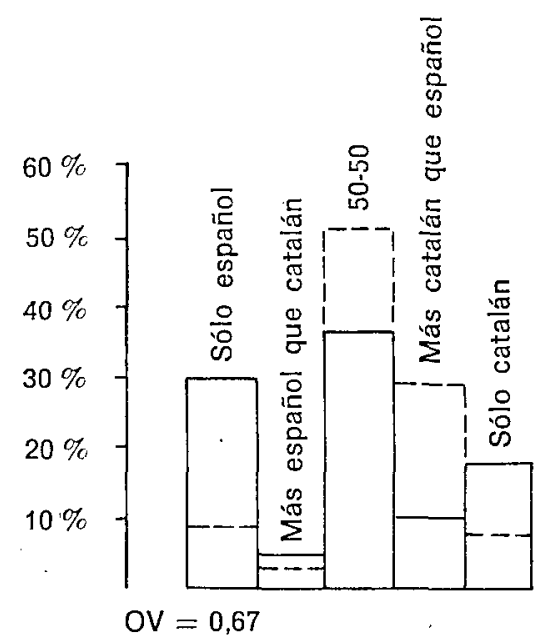

1982 운
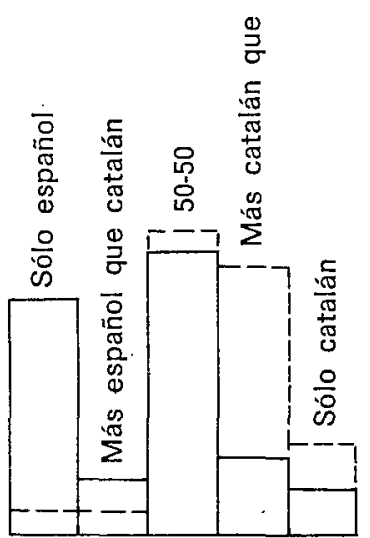

$\mathrm{OV}=0,64$

FIGURA D $b$

PSC-PSSOE
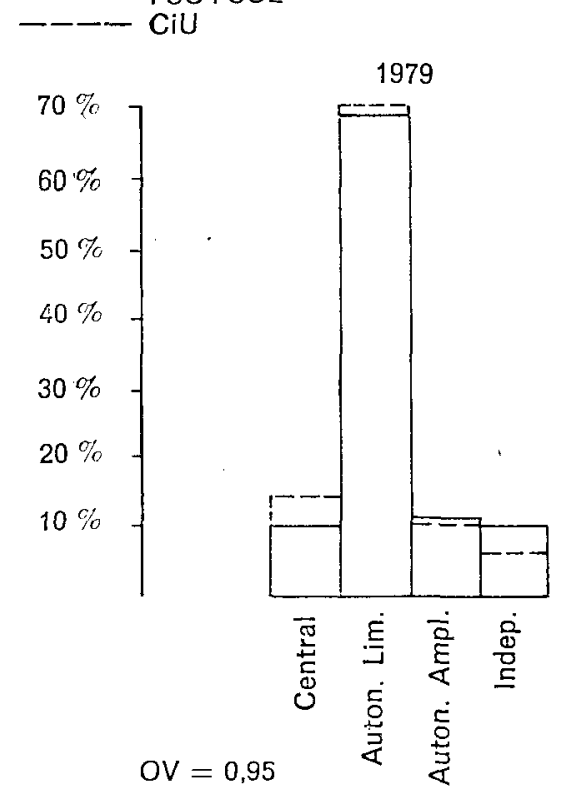

$1 \dot{9} \dot{2}$

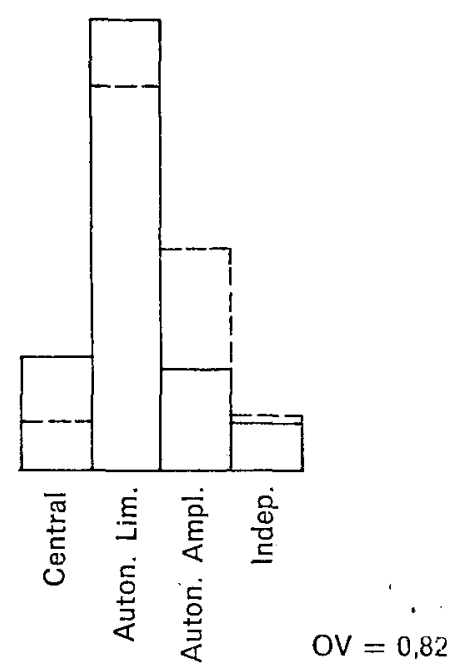


TABLA 9

VALORACION DEL GOBIERNO AUTONOMO CATALAN
SEGUN LOS VOTANTES DE CIU Y DEL PSC-PSOE

(En porcentajes)

\begin{tabular}{|c|c|c|c|c|c|c|}
\hline & $\begin{array}{c}\text { Muy } \\
\text { bueno }\end{array}$ & Bueno & $\begin{array}{c}\text { Ni bueno } \\
\text { ni malo }\end{array}$ & Mediocre & $\begin{array}{l}\text { Muy } \\
\text { malo }\end{array}$ & $(N)$ \\
\hline $\mathrm{CiU} \ldots \ldots \ldots c c c c$ & 13,4 & 60,2 & 20,7 & 5,1 & 0,7 & $(204)$ \\
\hline PSC-PSOE $\ldots \ldots \ldots$ & 0,4 & 22,4 & 44,4 & 19,6 & 13,2 & $(365)$ \\
\hline $\begin{array}{c}\text { Total regional } \\
\quad \text { OV }=49\end{array}$ & 3,6 & 32,4 & 36,1 & 18,1 & 9,9 & (1004) \\
\hline
\end{tabular}

Gobierno autónomo de $\mathrm{CiU}$, al impacto de la autonomía en la vida cotidiana y a la LOAPA. Como en el País Vasco, los seguidores del partido nacionalista estaban más dispuestos que los votantes socialistas a evaluar el funcionamiento del Gobierno autónomo en términos positivos. Entre los últimos, un tercio lo evaluaba como «mediocre» o «muy malo» (véase tabla 9). Los partidarios de PSC-PSOE se encontraban, además, menos favorablemente inclinados que los votantes de Convergencia a considerar beneficioso el impacto de la autonomía (el 53 por 100 frente al 72 por 100). La divergencia frente a la LOAPA era incluso mayor. El 68 por 100 de los votantes de Convergencia, contra el 37 por 100 de sus oponentes políticos, pensaba que podría limitar la autonomía regional. Entre los últimos, ésta era una proporción casi idéntica a la de aquellos que opinaban que mejoraría la autonomía. Y mientras que menos del 16 por 100 en cada uno de los dos grupos manifestaba abiertamente su apoyo a la LOAPA, el 72 por 100 de los votantes de CiU expresaba su desacuerdo, comparado con el 40 por 100 de los votantes socialistas; el resto no manifestaba su opinión. Así, al igual que en el País Vasco, la autonomía ha producido por sí misma nuevas y profundas diferencias dentro del sistema de partidos catalán.

Por todo ello, en ambas regiones la concesión de la autonomía llevó a una intensificación de las tensiones políticas entre los partidos regionales y estatales. Que tal fue el caso, a pesar de la relativa estabilidad de los dos sistemas de partidos, se demuestra más claramente en la creciente diferenciación en el comportamiento electoral de las comunidades de nativos y de inmigrantes en ambas regiones entre las elecciones de 1979 y las de 1982 (véase tabla 10). La muy probable victoria del PSOE en 1982 movilizó indudablemente a muchos inmigrantes de status ocupacional bajo, y con tendencias de izquierda, que se habían abstenido en previas elecciones, y alejó a otros de Herri Batasuna y Euskadiko Ezkerra. En Cataluña, la mayor divergencia en 1982 era más el resultado de cambios en el apoyo partidista de la población nativa que entre la inmigrante. En resumen, los sistemas de partidos vasco y catalán reflejaron en mayor medida que antes la división nativo-inmigrante, una manifestación crucial de las «escisiones» centro-periferia en el seno de las dos sociedades. 


\section{TABLA 10}

EL VOTO EN LAS ELECCIONES PARLAMENTARIAS DE 1979 Y 1982 DE LOS NATIVOS E INMIGRANTES EN EL PAIS VASCO Y CATALUNA (En porcentajes)

Pais Vasco, 1979

\begin{tabular}{|c|c|c|c|c|c|c|c|c|}
\hline & $\underset{\text { Batasuna }}{\text { Herri }}$ & $\begin{array}{c}\text { Euskadiko } \\
\text { Ezkerra }\end{array}$ & PNV & Comm. & Soc. & UCD & AP & $(N)$ \\
\hline $\begin{array}{cccc}\text { Inmigrantes } & \ldots & \ldots \\
\text { Nativos } & \ldots & \ldots & \ldots \\
\text { OV }=.61 & & \end{array}$ & $\begin{array}{ll}\ldots & 17,8 \\
\ldots & 22,6\end{array}$ & $\begin{array}{r}6,2 \\
11,7\end{array}$ & $\begin{array}{l}14,0 \\
42,5\end{array}$ & $\begin{array}{l}4,8 \\
0,8\end{array}$ & $\begin{array}{r}33,0 \\
8,0\end{array}$ & $\begin{array}{l}19,4 \\
10,6\end{array}$ & $\begin{array}{l}2,2 \\
1,6\end{array}$ & $\begin{array}{l}(199) \\
(417)\end{array}$ \\
\hline
\end{tabular}

Pais Vasco, 1982

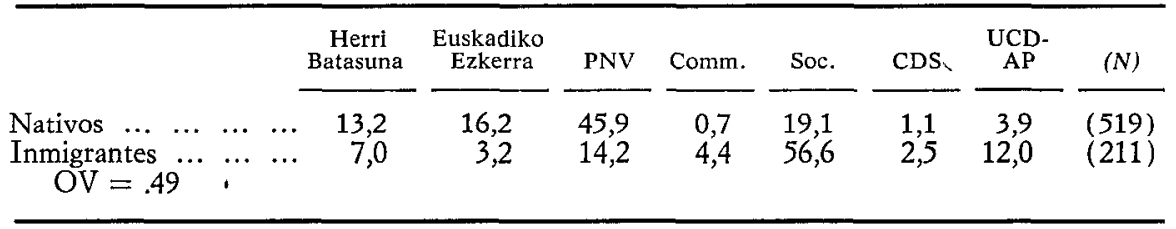

Cataluña, 1979

\begin{tabular}{|c|c|c|c|c|c|c|c|c|}
\hline & BEAN & ERC & $\mathrm{CiU}$ & PSUC & $\begin{array}{l}\text { PSC- } \\
\text { PSOE }\end{array}$ & UCD & AP & $(N)$ \\
\hline $\begin{array}{lllll}\text { Nativos } & \ldots & \ldots & \ldots & . .\end{array}$ & 1,0 & 6,8 & 14,5 & 11,3 & 34,5 & 24,8 & 3,9 & $(623)$ \\
\hline $\begin{array}{c}\text { Inmigrantes } \\
\mathrm{OV}=.91\end{array}$ & 0,9 & 2,2 & 5,0 & 16,4 & 46,2 & 23,8 & 2,4 & (321) \\
\hline
\end{tabular}

Cataluña, 1982

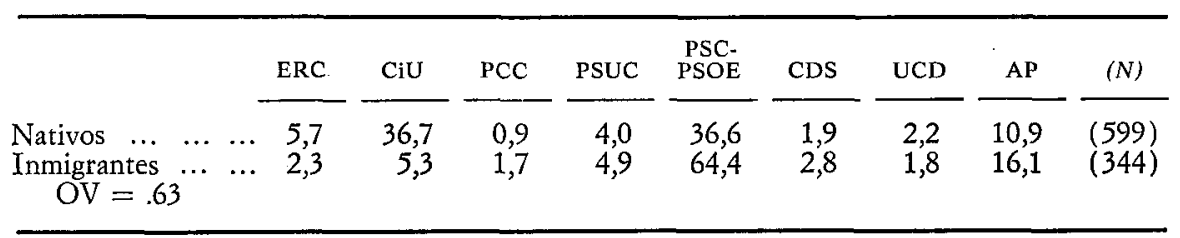

DIMENSIONES DE POLARIZACION:

IDEOLOGIA Y ANTAGONISMO POLITICO

El conjunto de problemas que componen los tres cleavages tradicionales no son, en cualquier caso, las únicas divisiones significativas que caracterizan al electorado español. Por el contrario, se pueden señalar otras áreas de problemas en torno a las que las diferencias entre los grupos políticos son bastante signifi- 
cativas. Una de estas áreas tiene que ver con las respuestas obtenidas a catcbwords referentes a principios «ideológicos» generales, tipo de régimen, política del pasado, etc. Tanto en 1979 como en 1982, a los entrevistados se les pidió que expresaran su reacción y preferencias ante términos presentados en forma de dicotomía, tales como «franquismo/antifranquismo», «marxismo/no marxismo», «propiedad privada o nacionalización», etc. Aunque la pauta de respuestas a estos estímulos está lejos de constituir un buen mapa de las diferencias ideológicas, las respuestas proporcionan algunas indicaciones básicas sobre la posición de los votantes en el universo político. Después de todo, estos términos hacen referencia a ideas $\mathrm{u}$ «objetos» políticos bien conocidos que han sido utilizados en el discurso político por un considerable período de tiempo y que en la mente de los votantes han sido asociados a los principales protagonistas políticos. Las respuestas dadas por nuestros entrevistados, divididas en términos de preferencias partidistas, se ofrecen en la tabla 11.

TABLA 11

ASPECTOS DE «DISTANCIA IDEOLOGICA» EN 1979 Y 1982

(En porcentajes)

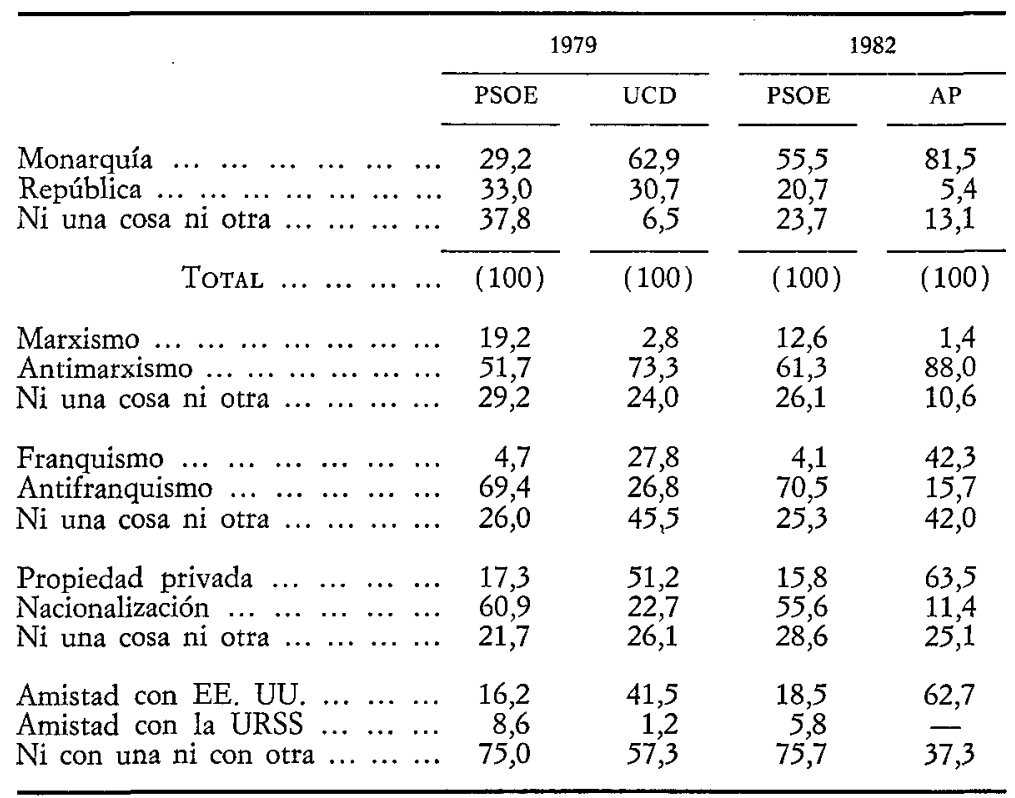

De inmediato, resulta evidente que, a este respecto, el realineamiento de 1982 ha producido también un significativo incremento en la distancia entre los principales grupos. En cuatro de las cinco dicotomías presentadas, el porcentaje 
de diferencias de 1982 es mayor que el de 1979. Correspondientemente, los valores de los coeficientes eta son más altos, indicando una mayor separación entre los dos grupos partidistas. El grado de diferenciación entre los grupos varía algo. en función del aspecto considerado. Toda vez que hay pocos votantes socialistas. que favorezcan una opción marxista y que sólo uno de cada cinco partidarios. del PSOE prefiere un régimen republicano, las diferencias en relación a estos. estímulos resultan menos marcadas. En el caso de otros conceptos, la yuxtaposición, sin embargo, resulta bastante evidente. «Propiedad privada vs. nacionalización» y aceptación/rechazo del franquismo son los conceptos que producen. un contraste más pronunciado. En el caso de la amistad hacia Estados Unidos.

GRAFICO 7.-Valoración de los líderes de los partidos mayoritarios, 1979 y 1982

1979

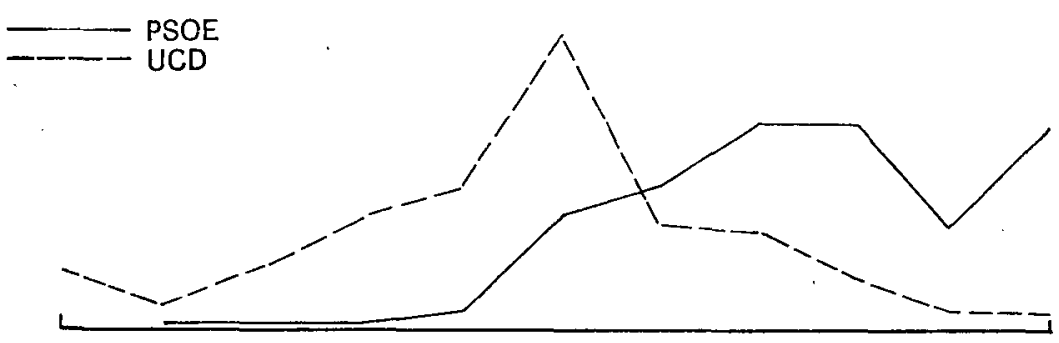

Negativo

Sentimientos hacia F. González

Positivo.

Media votantes PSOE: 7,4 Media votantes UCD: 4,7

$\mathrm{ETA}=0,54$

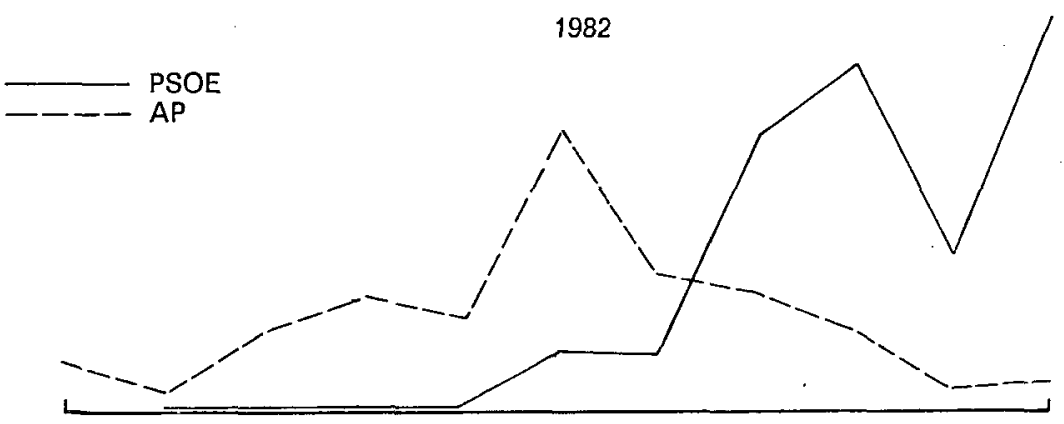

Negativo

Sentimientos hacia F. González

Positivo:

Media votantes PSOE: 8,2

Media votantes AP: $\quad 5,0$

$\mathrm{ETA}=0,63$. 
- la Unión Soviética, las diferencias intergrupos son algo menos pronunciadas, ya que los rusos no son populares en ninguno de los dos grupos. No obstante, el hecho de que tres votantes socialistas de cada cuatro adopte una posición neutral respecto de las dos principales potencias, mientras que tres de los partidarios de AP se manifiesten a favor de Estados Unidos, produce un significativo elemento de diferenciación entre los dos grupos de votantes.

Una dimensión adicional de división dentro del electorado hace referencia a los sentimientos de los votantes hacia los diferentes partidos y sus respectivos líderes. Es importante señalar que esta dimensión más estrictamente «partidista», aunque no sin relación con los diferentes problemas más importantes, tiene una cierta autonomía y dinámica propia. Los sentimientos hacia los líderes de otros partidos reflejan diversos grados de simpatía/hostilidad, que pueden ser explicados, en parte, en términos de distancia. Pero sólo en parte. Algunas consideraciones sobre los partidos y los políticos parecen estar fundadas menos en un cálculo de las opciones políticas y más en imágenes difusas y, a grandes rasgos, esbozadas de los protagonistas políticos, en las cuales el componente emocional/afectivo oscurece al cognitivo racional. Esto no los hace menos poderosos como factores de motivación o instrumentos que orientan a los electores en el mundo de la política. Veamos a continuación cómo estas apreciaciones sobre algunas de las principales figuras políticas varían entre los grupos partidistas.

En un trabajo anterior presentamos algunos datos sobre las pautas de antagonismo político que existía en España en 1979 y que mostraba que las percepciones de los partidos y de los políticos se encontraban fuertemente estructuradas por la posición de los votantes en el continuo izquierda-derecha ${ }^{22}$. Esta .estructuración es todavía mucho más evidente en los datos de 1982. Pero la pauta de simpatía u hostilidad hacia los políticos está también influido por su estilo personal, por las imágenes que los líderes han estado proyectando a lo largo del tiempo y que han calado en las mentes de los ciudadanos. Resulta que algunas de las figuras políticas más importantes tienen características que provocan opiniones negativas más fuertes que otras. En el panorama político espa.nol esto se aplica a Manuel Fraga Iribarne, y en Cataluña, a Jordi Pujol. En el caso de Fraga, este aspecto resalta de forma clara en los gráficos 6 y 7. En 1979 había una simetría remarcable en las valoraciones de los partidarios de UCD hacia el líder socialista Felipe González y en las evaluaciones de Suárez por los votantes socialistas. En ambos casos, la media de la «puntuación de simpatía» para el líder del «otro partido» era más bajo (como debía ser) que la puntuación para el líder del propio partido. Más baja, pero no excesivamente. Además, las evaluaciones del «otro» líder expresaban más frecuentemente sentimientos de neutralidad que de hostilidad, como confirma que la moda de la distribución se sitúe en el punto 5 . Esta pauta no se mantiene, sin embargo, en el caso de las valoraciones sobre Fraga. En 1982, los votantes socialistas dieron al líder de AP puntuaciones extremadamente bajas; como el gráfico indica, la moda de la distribución se situaba en el punto correspondiente a la evaluación más negativa. El examen de las distribuciones muestra que Fraga era la «bestia negra» de una cuarta parte de todos los votantes socialistas; además, puntuado bastante nega-

${ }^{22}$ Sani, «Partiti e atteggiamenti...», cit., espec. pág. 274. 
tivamente (puntuaciones de 1 y 2 ) por otro 25 por 100 de los simpatizantes del PSOE. La suposición de que esto podría reflejar un mutuo antagonismo, es decir, una similar disposición de los votantes de AP hacia Felipe González, no se puede apoyar en los datos. Los votantes de AP parecen ser mucho más «generosos» que sus oponentes: la actitud predominante hacia Felipe González es la de neutralidad e incluso medio aprobación. Ello indica que la obvia asimetría de las dos distribuciones es el producto de la poderosa, y para muchos irritante, personalidad de Fraga. En todo caso, cualesquiera que sean las razones, estos datos reflejan también que la distancia (en este caso «distancia de afecto») entre los dos grupos partidistas principales era mayor en 1982 que lo había sido en

GRAFICO 8.-Valoración de los líderes de los partidos mayoritarios, 1979 y 1982

1979

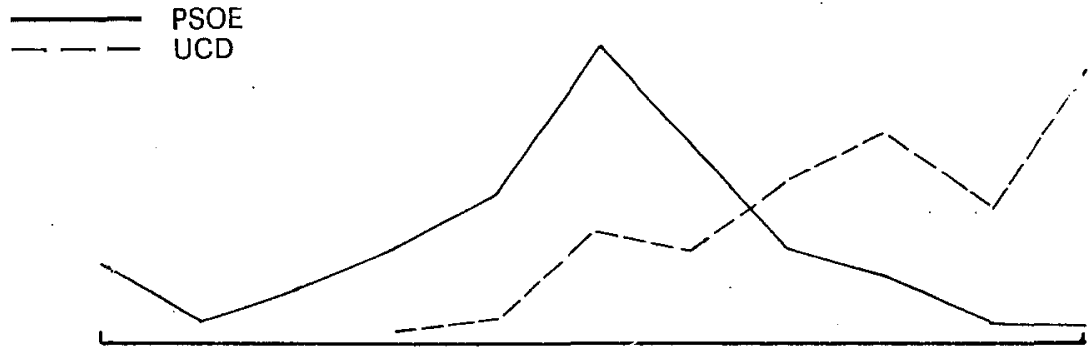

Negativo

Sentimientos hacia Suárez

Positivo

Media votantes PSOE: 4,7

Media votantes UCD: $\mathbf{7 . 8}$

$\mathrm{ETA}=0,58$

$\simeq{ }_{\mathrm{AP}}^{\mathrm{PSOE}}$

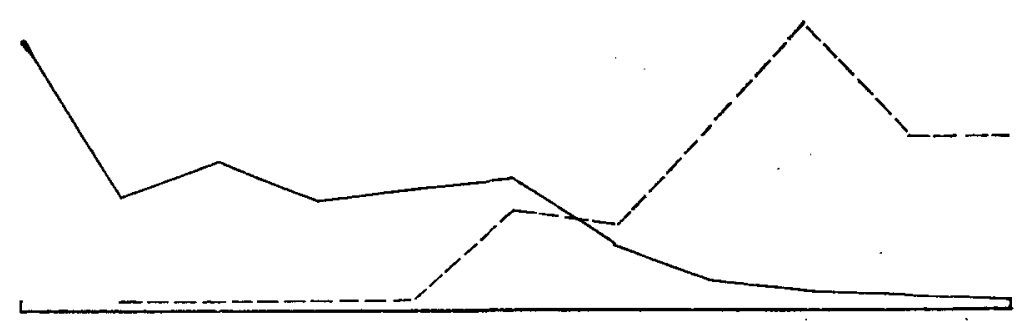

Negativo

Sentimientos hacia Fraga

Positivo

Media votantes PSOE: 2,7

Media votantes AP: $\quad 7,7$

$E T A=0,73$ 
1979. Efectivamente, Fraga tampoco era un favorito de los partidarios del PSOE en 1979. Pero en aquel momento no era el líder de la oposición, sino tan sólo uno de los nueve miembros del Congreso de los Diputados, que habían sido elegidos en la candidatura presentada por una coalición que recibió sólo el 6,1 por 100 de los votos a nivel nacional. En este supuesto, como en el caso de otras variables, el incremento en la polarización no tiene su origen en cambios actitudinales, en una radicalización a nivel de masas, sino en cambios en el status de los partidos en el sistema, en el nivel de su significación sistémica.

Tanto las distribuciones simétricas como asimétricas de las valoraciones de los líderes políticos aparecieron también en las dos regiones ${ }^{23}$. Las actitudes hacia Felipe González entre los seguidores de CiU y PNV en 1982 recordaban las de los votantes de UCD en 1979 y de AP en 1982, en tanto que manifestaban frecuentemente más sentimientos de neutralidad que de hostilidad. El líder del PNV, Carlos Garaicoechea, generaba una mayor división entre los votantes del PNV y los votantes socialistas que Felipe González. No obstante, había un cierto grado de simetría entre las dos distribuciones, dado que una mayoría de socialistas mostraban posiciones neutrales o positivas hacia la cabeza del Gobierno autónomo vasco. Semejante simetría se encontraba notablemente ausente en Cataluña. Mientras los partidarios de Convergencia declaraban, en términos generales, bastante simpatía hacia el líder socialista, no se podría decir lo mismo de las valoraciones de los votantes socialistas hacia el líder de CiU y cabeza del Gobierno catalán, Jordi Pujol: fue puntuado negativamente por el 48 por 100 del conjunto de los votantes del PSC-PSOE. Pujol parece ser una figura mucho más controvertida que Garaicoechea. Por el contrario, los partidarios de Convergencia eran sólo algo más proclives a expresar sentimientos positivos hacia el líder de su propio partido que hacia Felipe González. Pero el mayor grado de «distancia afectiva», superior incluso que el generado por Fraga, aparecía entre los votantes de HB y el PNV con respecto de sus sentimientos hacia Garaicoechea: un 9 por 100 de partidarios de HB mostraban simpatía hacia el líder del PNV.

El crecimiento de la polarización en relación a esta dimensión puramente partidista resulta confirmada por una última evidencia. Se ha argumentado en otro lugar que los sistemas de partidos polarizados se caracterizan por una extensa presencia de «preferencias negativas de partido» ${ }^{24}$. Expresión que puede ser definida como la existencia de vetos hacia un partido tan fuerte, que lo excluyen de ser considerado como una opción de voto. En 1979, a los españoles entrevistados por nosotros les fue preguntado si había partidos por los cuales ellos «nunca votarían». Las respuestas muestran que algunos partidos, siempre los más extremos, fueron señalados como opciones negativas más a menudo que otros, y que la «preferencia negativa» estaba fuertemente relacionada a la percepción de la distancia entre uno mismo y los diferentes partidos. Los datos de 1982 presentan una estructura de conjunto bastante similar (tabla 12). El cambio más acusado parece ser un nivel menor de exclusión entre los votantes de AP hacia el PSOE en 1982 que en 1979, un resultado que es perfectamente

${ }^{23}$ No nos es posible comparar la evolución de los sentimientos hacia los líderes políticos regionales por no haber incluido la correspondiente pregunta en la encuesta de 1979.

2* Sani, «Partiti e atteggiamenti...», cit. 
comprensible, dado el masivo influjo de los antiguos votantes de UCD en las filas de AP. No ha habido cambio, sin embargo, en las reservas que los votantes del PSOE mantenían hacia AP. Evidentemente, para muchos votantes socialistas poco ha cambiado en la naturaleza de AP que pueda hacer a este partido más aceptable. Pero desde esta continuidad de actitudes se podría deducir una ausencia de cambio en el nivel de polarización. El hecho de que se mantengan las mismas actitudes hacia un partido adquiere un significado muy diferente cuando las tendencias electorales convierten a un pequeño contingente de votantes en la segunda fuerza política del país ${ }^{25}$.

\section{RESUMEN E IMPLICACIONES}

Nuestro análisis de las diferencias actitudinales entre los dos principales grupos de electores a escala nacional ha confirmado el diagnóstico inicial basado en las distribuciones de los votantes sobre el continuo ideológico izquierdaderecha. Se ha demostrado que, prácticamente con respecto de todas las áreas de problemas considerados, ha habido un incremento en la distancia que separa a los seguidores de los dos partidos principales. El colapso de UCD y la división de su base electoral en dos subgrupos que se dirigieron al PSOE y AP ha incrementado la distancia (sociológica, afectiva e ideológica) entre los dos nuevos partidos líderes. El incremento en el nivel de polarización se ha debido más a los cambios en la fortuna electoral de los partidos que a una radicalización en las actitudes de masas. El crecimiento de la polarización no fue uniforme. En algunos casos, por ejemplo el de la religiosidad, ha habido poco cambio e incluso quizá un ligero descenso. En otros, por ejemplo el de clase, las diferencias en la base ocupacional de los partidos o en la identificación subjetiva de clase se ha profundizado. El análisis discriminante múltiple en el que todas las variables aquí consideradas fueron tenidas en cuenta simultáneamente, indica que el grado total de separación entre el PSOE y AP era considerable: un total del 95 por 100 de los entrevistados estaba correctamente asignado a sus respectivos grupos. Esto representa un incremento en varios puntos sobre el grado de separación que, en 1979, mostraban los partidarios del PSOE y UCD ${ }^{26}$.

De forma similar, un examen de las actitudes de los principales grupos partidistas en el País Vasco y Cataluña tiende a confirmar nuestras suposiciones iniciales. Incluso, aunque el realineamiento de 1982 tuvo menores consecuencias en términos de los principales protagonistas políticos, los dos sistemas regionales de partidos experimentaron un crecimiento de la polarización con respecto de los problemas centro-periferia. Ello se debió en gran medida a las tensiones sobre la concesión y desarrollo de la autonomía regional. En el País

${ }^{25}$ Que existe un grado mayor de antagonismo entre los partidarios de los dos partidos nacionalistas vascos que entre los socialistas y los seguidores del partido regional moderado se confirma también al considerar sus «preferencias negativas de los partidos». Poco más de la mitad de los partidarios de HB manifestaron en 1982 que nunca votarían al PNV. En ningún otro caso, la proporción de preferencia negativa hacia el grupo opuesto excedió un tercio.

${ }_{26}$ Los valores del coeficiente lambda de Wilks fueron .44 en 1979 y .32 en 1983; el coeficiente de correlación canónica se incrementó de .75 a .82 . 
Vasco, la polarización fue más destacable entre las dos fuerzas nacionalistas principales. En Cataluña, en la que las diferencias partidistas fueron menos profundas que en la región vasca, nuevos problemas relacionados con la autonomía han generado desacuerdos pronunciados entre CiU y el PSC-PSOE.

¿Cuáles son las implicaciones de este análisis para la nueva configuración del sistema de partidos español? A través de este trabajo hemos hecho énfasis en la polarización. Pero no es ésta la única consecuencia del realineamiento de 1982. Una segunda y significativa consecuencia ha sido la simplificación del sistema de partidos, al menos en el nivel nacional. La fragmentación tanto en términos de votantes como de escaños en el Congreso se ha visto reducida. La desaparición de UCD de la escena política y la modesta fuerza electoral demostrada por el centrista CDS parece haber empujado al sistema de partidos español en la dirección de la bipolaridad. Consideradas conjuntamente, estas tendencias sugieren que España podría estar moviéndose en la dirección de un sistema de partidos habitualmente denominado two party plus. Sin embargo, los sistemas que pertenecen a este tipo se caracterizan usualmente también por un grado de polarización de bajo a moderado. Con referencia a este último aspecto, el sistema de partidos español se diferenciaba de otros sistemas europeos, como el británico o el alemán. Ello aparece claramente en el gráfico, que muestra las distribuciones en la escala izquierda-derecha de los votantes de los principales partidos en los tres países. Los datos de Alemania y Gran Bretaña se encuentran un poco desfasados (mitad de los setenta), pero para nuestros propósitos no es demasiado importante. Resulta evidente en ese gráfico que en estos dos clásicos sistemas de two party plus el solapamiento entre los principales electorados es mayor que en el caso español, cuyos dos principales bloques se encuentran más nítidamente separados y por una distancia más amplia.

TABLA 12

PREFERENCIAS NEGATIVAS DE PARTIDO EN 1979 Y 1982

\begin{tabular}{|c|c|c|}
\hline & $\%$ & $(\mathrm{~N})$ \\
\hline \multicolumn{3}{|l|}{ 1979: } \\
\hline Votantes de UCD que «nunca votarían PSOE $» \ldots \ldots \ldots \ldots$ & 15,5 & (1658) \\
\hline 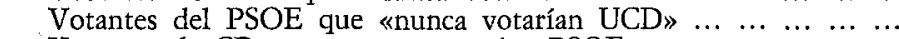 & 24,8 & (1354) \\
\hline Votantes de $\mathrm{CD}$ que $\ll$ nunca votarían $\mathrm{PSOE} » \ldots \ldots \ldots \ldots$ & 42,0 & $(172)$ \\
\hline 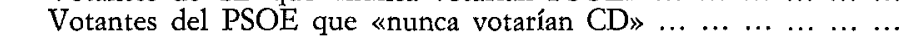 & 56,0 & (1354) \\
\hline \multicolumn{3}{|l|}{ 1982: } \\
\hline Votantes de AP que «nunca votarían PSOE» $\ldots \ldots \ldots \ldots \ldots \ldots$ & 28,7 & $(882)$ \\
\hline 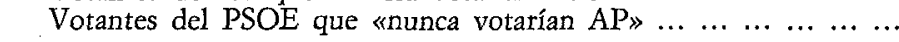 & 56,9 & (2060) \\
\hline
\end{tabular}

Una complicación adicional de la política española es la consolidación de específicos sistemas de partidos regionales, cuya importancia trasvasa la política local. Incluso aunque el apoyo de las fuerzas nacionalistas no sea necesario para sostener el Gobierno después de la aplastante victoria socialista, la relevancia 
de estos grupos para la política nacional no ha disminuido en ningún caso. De hecho, puede haberse incrementado. La posibilidad de que crezca el aislamiento y/o la exclusión de estos grupos minoritarios del proceso de decisión en el nivel nacional, particularmente sobre los problemas centro-periferia, puede fomentar la desintegración política más que la integración.

La polarización de la política española es, quizá, un fenómeno temporal, una tendencia que podría desaparecer a medida que el sistema se consolide. Se mantiene, sin embargo, una característica distorsionante, especialmente cuando se consideran las diferencias en la fuerza electoral de los principales partidos. Una mayoría dominante frente a una o varias minorías resentidas, con pocas posibilidades de desempeñar un papel diferente, a corto plazo, no es una buena combinación para que la democracia funcione. Será necesario habilidad y moderación por parte de las elites políticas para contrarrestar las fuerzas centrífugas.

(Traducción: Pilar del Castrllo Vera.) 